\title{
Vapor transport, grain growth and depth-hoar development in the subarctic snow
}

\author{
Matthew Sturm, ${ }^{1}$ Carl S. Benson ${ }^{2}$ \\ ${ }^{1}$ U.S. Army Cold Regions Research and Engineering Laboratory, P.O. Box 35170, Ft. Wainwright, Alaska 99703-0170, U.S.A. \\ ${ }^{2}$ Geophysical Institute, University of Alaska, Fairbanks, Alaska 99775, U.S.A.
}

\begin{abstract}
Measurements from the subarctic snowpack are used to explore the relationship between grain growth and vapor flow, the fundamental processes of dry-snow metamorphism. Due to extreme temperature gradients, the subarctic pack undergoes extensive depth-hoar metamorphism. By the end of the winter a five-layered structure with a pronounced weak layer near the base of the snow evolves. Grain-size increases by a factor of $2-3$, while the number of grains per unit mass decreases by a factor of 10 . Observed growth rates require significant net inter-particle vapor fluxes. Stable-isotope ratios show that there are also significant net layer-to-layer vapor fluxes. Soil moisture enters the base of the pack and mixes with the bottom $10 \mathrm{~cm}$ of snow, while isotopically light water vapor fractionates from the basal layer and is deposited up to $50 \mathrm{~cm}$ higher in the pack. End-of-winter density profiles for snow on the ground, compared with snow on tables, indicate the net layer-to-layer vapor flux averages $6 \times 10^{-7} \mathrm{~kg} \mathrm{~m}^{-2} \mathrm{~s}^{-1}$, though detailed measurements show the net flux is episodic and varies with time and height in the pack, with peak net fluxes ten times higher than average. A model, driven by observed temperature profiles, reproduces the layer-to-layer flux pattern and predicts the observed weak layer at the base of the snow. Calculated layer-to-layer vapor fluxes are ten times higher than inter-particle fluxes, which implies that depth-hoar grain growth is limited by factors other than the vapor supply. This finding suggests that gain and loss of water molecules due to sublimation from grains takes place at a rate many times higher than the rate at which grains grow, and it explains why grains can metamorphose into different forms so readily.
\end{abstract}

\section{LIST OF SYMBOLS}

a Slope, linear regression for snow depth

$b \quad$ Intercept, linear regression for snow depth

c Slope, linear regression for snow density

$c_{0}, c_{1} \quad$ Curve-fitting coefficients

$d \quad$ Intercept, linear regression for snow depth

$\bar{d} \quad$ Mean grain diameter

$\overline{D_{j, j+1}}$ Average of the mesh opening of the $j$ th and the $j+$ th sieves

$D_{0}$

e

Water-vapor diffusion coefficient in air

Uncertainties in a calculated value

Enhancement factor

Number of grains per unit mass

Initial number of grains in the sample

Layer thickness

Condensation rate of water vapor per unit area of grain

Vertical water-vapor flux

Latent heat of sublimation $\left(2838 \mathrm{~J} \mathrm{~g}^{-1}\right.$ )

Number of sieves

Mass of $i$ th grain

Total weight fraction in the $j$ th sieve

Average mass of a grain in the $j$ th sieve

Number of grains per unit volume

Number of grains in the $j$ th sieve

Total number of grains in a sample

Gas constant for water vapor $\left(0.4619 \mathrm{~J} \mathrm{~g}^{-1}{ }^{\circ} \mathrm{C}^{-1}\right)$

Grain radius $(\mathrm{mm})$

$\begin{array}{ll}r_{\infty} & \text { Radius after a long period of time } \\ r_{0} & \text { Initial radius } \\ S & \text { Surface area of grain } \\ t & \text { Time } \\ T & \text { Temperature } \\ T_{0} & \text { Temperature at the melting point }\left(0^{\circ} \mathrm{C}\right) \\ V & \text { Volume of ice particle } \\ v & \text { Vertical convective velocity } \\ z & \text { Vertical coordinate } \\ \alpha & \text { Constant, equal to } 0.0001266 \\ \beta_{1}, \beta_{2} & \text { Constants } \\ \rho & \text { Density of snow } \\ \rho_{\mathrm{i}} & \text { Density of ice } \\ \bar{\rho}_{\mathrm{S}} & \text { Layer density } \\ \rho_{\mathrm{v} 0} & \text { Water-vapor density at the melting point } \\ & \left.\quad \text { (4.847 } \mathrm{m}^{-3}\right) \\ \phi & \text { Porosity }\end{array}$

\section{INTRODUCTION}

Dry snow will metamorphose into large, ornate depth-hoar grains when subjected to a strong temperature gradient. If the gradient is weaker, the grains will still grow, but depthhoar characteristics may be less conspicuous or absent. Under both weak and strong gradients, the grain growth is fed by water-vapor transport through the pore spaces of the snow. The two processes, grain growth and vapor transport, are the basis of dry-snow metamorphism. Combined, 
they control the movement and redistribution of mass, chemical species and isotopes in the snowpack. They also control the grain- and bond-size distribution, and therefore the thermal and mechanical properties of the snow. Though the two processes are intimately linked, we know surprisingly little about their relationship.

The existing literature does little to help. Most papers on dry-snow metamorphism are descriptive or theoretical. Of the few sets of measurements of vapor-transport or graingrowth rates, only one (de Quervain, 1958) contains simultaneous measurements of both processes. One reason for the scarcity of data is that there is no direct method of measuring vapor transport, which often produces changes in mass too small to be detected. Also, it is difficult to define, let alone measure, grain-growth rates. But perhaps the fundamental reason is the perception that transport and growth were adequately measured years ago. In our opinion, this is not the case, and the lack of data has delayed an understanding of snow metamorphism.

In this paper we present an extensive set of measurements, including simultaneous measurements of grain growth and vapor transport. It is the culmination of more than 30 years of work on the subarctic snowpack, which is ideal for observing both processes because they are accelerated due to the extreme temperature gradients (Fig. 1). To track both vapor flow and grain growth, we have used many techniques. The development of a distinctive depthhoar textural sequence was documented by direct observation and photomicroscopy. Changes in the number of grains and estimates of grain-growth rates have been computed from photogrammetric and sieve measurements. Density and layer-thickness measurements have been used to calculate net vapor-transport rates between layers of snow. Measurements of stable isotopes allowed us to determine the distances over which the vapor travels. Extensive sets of vertical temperature profiles have been used with a model to calculate in a detailed manner where in the snowpack the water vapor comes from and where it is deposited.

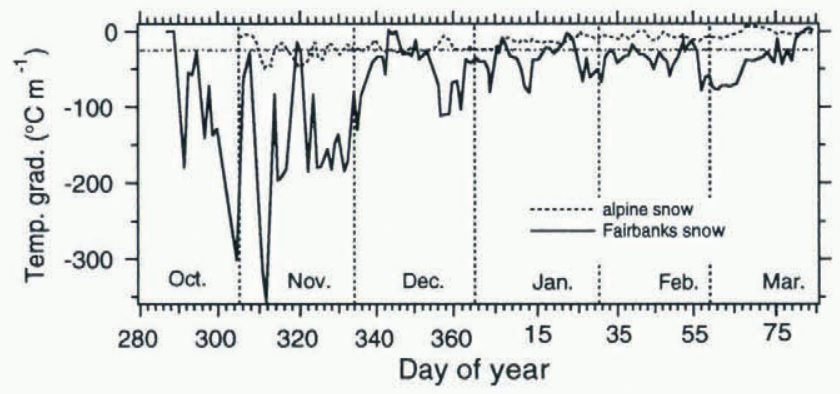

Fig. 1. The bulk vertical temperature gradient for the subarctic snow cover near Fairbanks. The temperature gradient from an alpine snow cover in Colorado (Armstrong, 1985) is shown for comparison. The critical gradient necessary for kinetic growth and depth-hoar development is shown as a dot-dash line.

We chose to work in a natural snow cover because we felt it was difficult or impossible to reproduce snowpack conditions adequately in the laboratory. But as a consequence of this choice, errors associated with individual measurements were substantial. We addressed the problem by replicating measurements and doing them year after year. We also measured key processes using multiple techniques, and have calculated vapor-transport rates by several independent methods. Results have been consistent, so we have confidence in their validity.

What emerges from our measurements is a picture of a vigorous, layer-to-layer vapor transport. A continuous flux of water vapor moves from the soil into the snow. Basal snow layers lose vapor to upper layers, leading to the development of a conspicuously weak depth-hoar layer near but not at the base of the snow. At the same time, there is rapid grain growth. Grains increase in size by a factor of $2-3$, while the total number of grains decreases by a factor of 10 . The graingrowth rates require net inter-particle flux rates that turn out to be about one-tenth of the magnitude of the net layerto-layer flux rates. This leads us to conclude that significant grain growth and depth-hoar development could take place even if layer-to-layer transport rates were reduced, and it suggests why grains can metamorphose so readily.

Yosida (1955) developed a description of "hand-to-hand" transfer of water-vapor molecules through the snow that has become a virtual paradigm for the way we think of the relationship between vapor transport and grain growth. In the "hand-to-hand" model, water-vapor molecules condense on the bottom of an ice grain, while other molecules sublimate from the top, thereby producing a continuous flow of vapor. If the two rates do not balance, the grain grows or shrinks. But at what rate do water-vapor molecules condense and sublimate from a grain? How far can individual water molecules travel before becoming incorporated in a grain? We believe the measurements we present below show that the rates of condensation and sublimation are quite high. The water molecules comprising a grain apparently change many times over during the course of the winter, resulting in grains that can metamorphose with extreme rapidity, even if their size changes little. Water molecules are highly mobile since they do not reside long on an individual grain. Hence, they can travel distances as great as the snow depth during the winter, albeit traveling the distance in a series of short hops from grain to grain.

\section{EXPERIMENTAL SETTING}

Measurements were made at the University of AlaskaFairbanks Agricultural Experiment Station $\left(64^{\circ} 49^{\prime} \mathrm{N}\right.$, $\left.147^{\circ} 52^{\prime} \mathrm{W}\right)$. The region has a dry, continental climate with continuous snow cover from October to April; forested areas and valley bottoms are nearly windless because of strong and persistent inversions. Low winter air temperatures $\left(<-25^{\circ} \mathrm{C}\right)$ are common, and above-freezing temperatures virtually absent. The temperature at the base of snow pack remains below freezing all winter, averaging $5^{\circ} \mathrm{C}$ (Sturm and others, 1995). Deeper in the soil the temperature is higher, so there is a continuous flux of heat and moisture from the soil to the snow. The source of the heat flux, which averages about $4 \mathrm{~W} \mathrm{~m}^{-2}$, is the cooling of the soil (negligible), the freezing of ample soil moisture $\left(3 \mathrm{~W} \mathrm{~m}{ }^{-2}\right)$ and the sublimation of about $0.5 \mathrm{~g} \mathrm{~cm}^{-2}$ of ice from the soil to the snow $\left(1 \mathrm{~W} \mathrm{~m}^{-2}\right)$ (Sturm, 1989, 1991; Sturm and Johnson, 1991). The low air temperatures and relatively high soil temperatures also produce extreme temperature gradients across the snowpack (Fig. 1) that create water-vapor density gradients which lead to rapid kinetic crystal growth and the development of a snow cover that consists mainly of depth hoar. By the middle of winter, the 
subarctic snowpack is less dense, more permeable and coarser grained than snowpacks found in more temperate climates.

Measurements at the experimental site extend back to 1963 (Trabant, 1970; Trabant and Benson, 1972; Johnson and others, 1987; Sturm, 1989, 1991; Friedman and others, 1991; Sturm and Johnson, 1991, 1992). Detailed measurements were made during the winter of 1986-87.

\section{METHODS}

Measurements of snow grain-size and character, snow density and layer thickness, snow temperature and stable isotopes were made on three types of samples: (1) from snow on the ground, (2) from snow on the ground but above an impermeable tarpaulin, and (3) from snow on tables. The snow on the ground but above the tarpaulin was isolated from the flux of moisture from the soil, but otherwise was subjected to the same heat flux as natural snow. Because cold air could circulate under the tables, the snow there was not subjected to strong temperature gradients and did not metamorphose into depth hoar (see the experiments of Kojima, 1959; Trabant and Benson, 1972; Armstrong, 1985). It also underwent negligible isotopic fractionation, which enabled us to use it to define the initial isotopic composition of the snowpack against which changes in the composition of the snow on the ground could be compared.

\section{Grain-size}

The grain-size was measured by sieving. It is a fast, efficient method that samples a large number of grains. We used a stack of nine sieves, each $20 \mathrm{~cm}$ in diameter. Snow samples were collected monthly from each snow layer during the winter of $1986-87$. Each sample $\left(500 \mathrm{~cm}^{3}\right)$ was gently sheared across the mesh of the top sieve to break it apart. In most cases the samples were quite fragile and this happened readily. Once the sample was disaggregated, the sieve stack was agitated by hand for $60 \mathrm{~s}$ with a rocking motion. After agitation, the snow fraction in each sieve was weighed with an accuracy of $\pm 0.1 \mathrm{~g}$. The work was done at or below $-18^{\circ} \mathrm{C}$ to prevent snow from sticking to the sieves.

At one time, sieving was widely used in snow studies (Bader and others, 1954; Benson, 1962; Keeler, 1969; Fukue, 1977; Granberg, 1985), but it has seen less use recently because it requires disaggregation of the snow sample, breaking snow grains as well as bonds, creating a bias toward smaller sizes. However, "the bond between individual grains is substantially weaker than the individual grains, so that it is possible to prepare a cohesionless, siftable mixture from cohesive snow without breaking up individual crystals to an appreciable extent" (Bader and others, 1954; see also Kry, 1975). Moreover, microscopic examination of snow fractions after sieving (unpublished information from M. Sturm, 1992) confirms that most grains remain intact, particularly for depth hoar where the bonds between grains are small in relation to the grains themselves.

The average grain-size determined by sieving was compared with the average size determined by photogrammetric methods. For two snow layers, samples were collected six to ten times during the winter. Part of each sample was sieved, and part was disaggregated onto a black background and photographed using a Zeiss Tessovar microscope. From the photographs, 50-200 grains were digitized by tracing their outlines with the stylus of a ZeissPlot stereological system. The mean cross-sectional area of the digitized grains was determined and reported as the diameter of a circle with the equivalent area.

\section{Density and layer thickness}

During 11 winters, between 1966 and 1987, we systematically measured the density profile of snow on the ground and the tables several times a winter. In 1986-87 the density and thickness of ten layers of snow on the ground and the comparable ten layers on the tables were measured approximately twice a month. Since depth-hoar metamorphism obliterated all primary natural stratigraphic markers in the snow on the ground (but not on the tables where depth hoar did not develop), it was necessary to introduce artificial markers to identify these layers. On both the ground and the tables, colored powder was spread on the snow surface after each snowfall. In this way, the upper and lower boundaries of layers were delineated and it was possible to make density and grain-size measurements tied to individual layers. Snow compaction was computed from measured changes in thickness of the snow between layers (accuracy $\pm 3 \mathrm{~mm}$ ). Little or no cross-boundary migration of snow grains was observed.

Density was measured using a $100 \mathrm{~cm}^{3}$ cutter and standard techniques (National Research Council of Canada, 1954; unpublished information from U.S.A. Snow, Ice and Permafrost Research Establishment, 1962; Carroll, 1977). The cutter could sample individual layers thicker than $3 \mathrm{~cm}$. Multiple measurements were made on each layer, and the results averaged. Fine-grained and new snow could be sampled with a reproducibility of $\pm 2 \%$, so the average of several density measurements is estimated to have the same accuracy. For depth hoar, which is fragile and more difficult to sample, reproducibility was $\pm 7 \%$.

\section{Temperature}

Individual vertical temperature profiles in the snow were measured hundreds of times from 1963 onwards using dial thermometers or thermistors. Continuous (hourly) profiles were monitored at the experimental site in 1984-87 using a data logger and an array of thermistors described by Sturm (1989, 1991) and Sturm and Johnson (1992). Additional continuous monitoring was done in 1989-90 and 1991-92 at a site $15 \mathrm{~km}$ away (Sturm and others, 1995) using a similar method.

\section{Isotopic ratios}

Stable-isotope ratios of ${ }^{18} \mathrm{O}$ to ${ }^{16} \mathrm{O}$ and of deuterium to hydrogen were measured during 11 winters between 1966 and 1987. Snow samples $\left(500 \mathrm{~cm}^{3}\right)$ were collected sequentially from top to bottom at the end of winter, before the thaw. Analysis protocols are described by Friedman and others (1991). Results are expressed relative to Vienna Standard Mean Ocean Water (V-SMOW) in standard delta units $\left(\delta \mathrm{D}\right.$ and $\left.\delta^{18} \mathrm{O}\right)$ in parts per thousand (per mil). The isotope ratios were used to track the transport of water vapor from the soil to the snow and upward within the snow. In effect, water vapor from the soil, which is isotopically heavier (higher values of $\delta \mathrm{D}$ and $\delta^{18} \mathrm{O}$ ) than the overlying snow, was used as a natural tracer. The isotope ratio of the soil moisture was measured by collecting the ice that 
formed under the impermeable tarpaulin at the end of winter. The vapor flux out of the soil was also measured by collecting this ice from a known area and weighing it.

\section{RESULTS}

\section{A depth-hoar metamorphic sequence}

Metamorphism in the subarctic snow results in the development of a sequence of five distinct textural layers (Fig. 2; Table 1). The uppermost layer (Ml) consists of new or recent snow. The underlying layers exhibit kinetic crystalgrowth forms and would be called either "solid" or "skeletal" depth hoar (Akitaya, 1974). The top two depth-hoar layers (M2 and M3) have textures that are common. They appear in the International Classification of Seasonal Snow on the Ground (ICSSG; Colbeck and others, 1990) as types $4 \mathrm{a}$ and $4 \mathrm{~b}$, or $5 \mathrm{a}$ and $5 \mathrm{~b}$ if they tended to form vertical chains of cups. Layer M4, consisting of squat, eroded prisms of depth hoar, has no textural analog in the ICSSG and does not seem to form in moderate climates. Characteristically, its columnar prisms have sharp, striated lower edges, but smooth, eroded upper edges indicative of growth at the bottom and mass loss by sublimation at the top. It is noticeably the weakest layer in the snowpack, often collapsing spontaneously or due to a slight jarring. Layer M5 would be classified as 5c in the ICSSG, and the inclusion of this texture and the type example used in the ICSSG comes from observations made during this study.

The sequence described above is both stratigraphic and metamorphic. As a layer of snow metamorphoses, it evolves from M1 to M2 and so on. Consequently, layers at the base of the snow exhibit more "advanced" stages of depth-hoar metamorphism than those above. Not only have the lower layers been subjected to temperature gradients longer than the overlying layers, but they have also experienced stronger gradients, since metamorphism early in the winter occurs when the snow pack is thinner (Fig. 1).

\section{Changes in grain-size and number}

Mean grain-size of a sieve sample was calculated using the following equation (Friedman and Sanders, 1983):

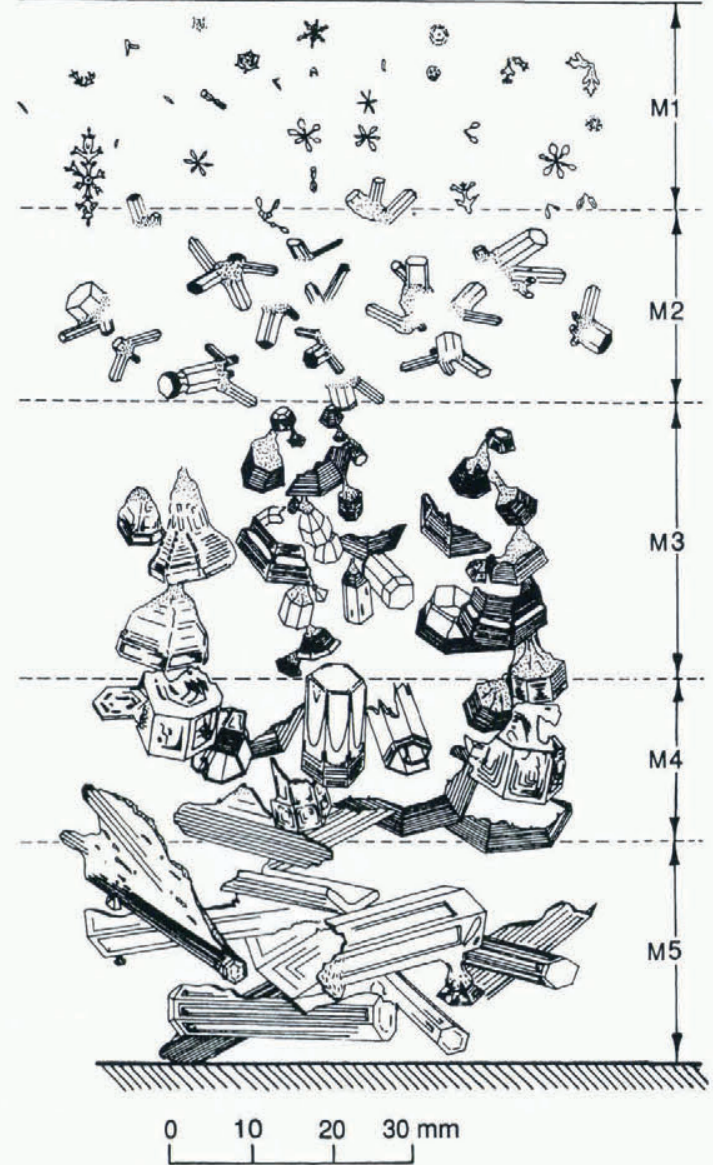

Fig. 2. The stratigraphic sequence of snow textures (crystal and grain morphologies) typically found in the subarctic snow cover during the winter. It is also a metamorphic sequence for individual layers of snow, with layers progressing from MI toward M.5. See Table I and text for layer descriptions.

$$
\bar{d}=\frac{\sum_{j=1}^{L} M_{\mathrm{j}} \overline{D_{j, j+1}}}{100}
$$

where $\bar{d}$ is the mean grain diameter for the sample, $M_{j}$ is the weight fraction in the $j$ th sieve, and $\overline{D_{j, j+1}}$ is the average of

Table 1. Five metamorphic textures of subarctic snow

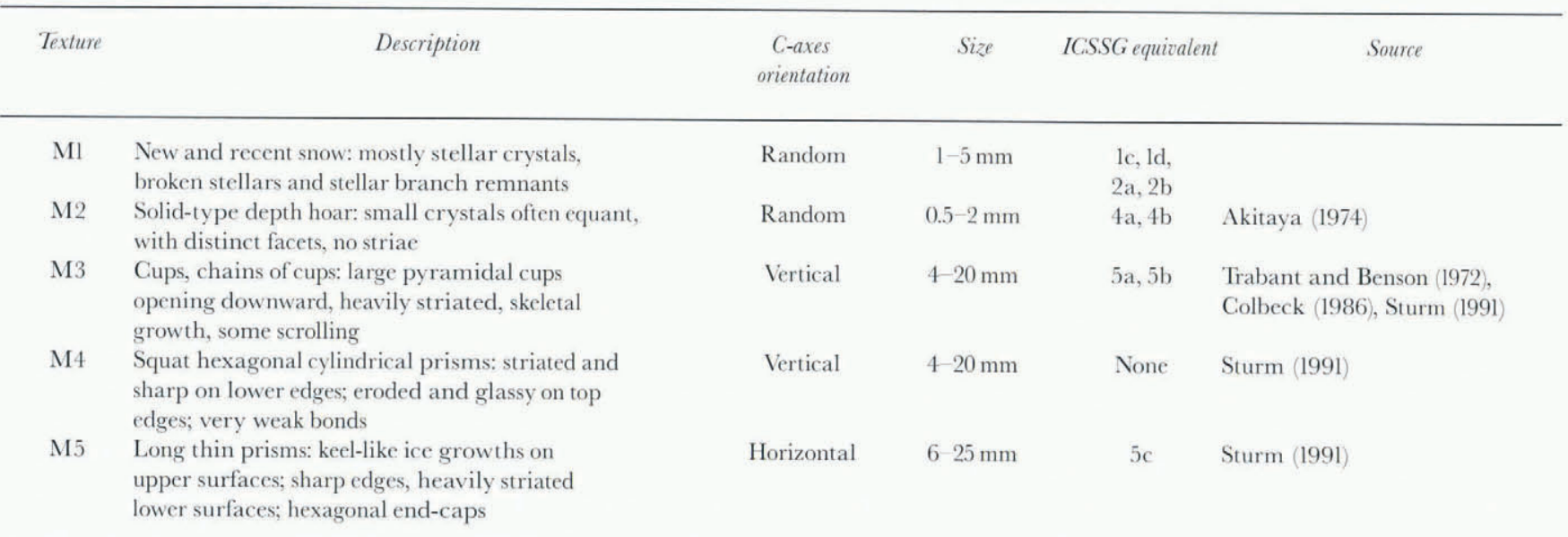


the sieve-mesh opening of the $j$ th and $j+1$ th sieves, with a total of $L$ sieves.

From the sieving, grain distributions were also determined. Normally, a size distribution is determined from the weight fraction in each sieve (Royse, 1970; Blatt and others, 1972; Friedman and Sanders, 1983) based on the premise that the size of a grain is related to the size of the sievemesh opening through which it passed. For spheres and other simple, regular shapes, this is true (Ludwick and Henderson, 1968), but for highly convoluted shapes like depth hoar, a simple relationship may not exist. To avoid complicated and possibly arbitrary conversions between grain-size and sieve size, we dealt directly in grain mass. For several representative depth-hoar samples, the individual grains in each sieve were weighed to establish a relationship between the sieve-mesh size and the average mass of the grains in the sieve (Fig. 3). Bader and others (1954) performed a similar procedure, and their data (Fig. 3) agree well with ours.

The data were fit with a polynomial:

$$
\bar{m}_{j}=\alpha\left(\overline{\frac{D_{j, j+1}}{2}}\right)^{3}
$$

where $\bar{m}_{j}$ is the average mass $(\mathrm{g})$ of a grain in sieve, $\overline{D_{j . j+1}}$, in $\mathrm{mm}$, is defined in Equation (1) and $\alpha=0.0001266$. If a collection of perfect ice spheres were sieved, the value of $\alpha$ would equal 0.0001698 (dotted line in Fig. 3). The curve for depth hoar lies surprisingly close to the curve for spheres, and it is likely that more rounded snow textures would lie even closer. Using Equation (2), the average mass of a grain caught in a particular sieve can be determined. Since the total weight fraction of snow in the sieve was measured, the total number of grains in each sieve could be estimated. Summing for all sieves permitted the total number of grains in a sample to be estimated as well (Appendix A).

Average grain-sizes determined by sieving and from

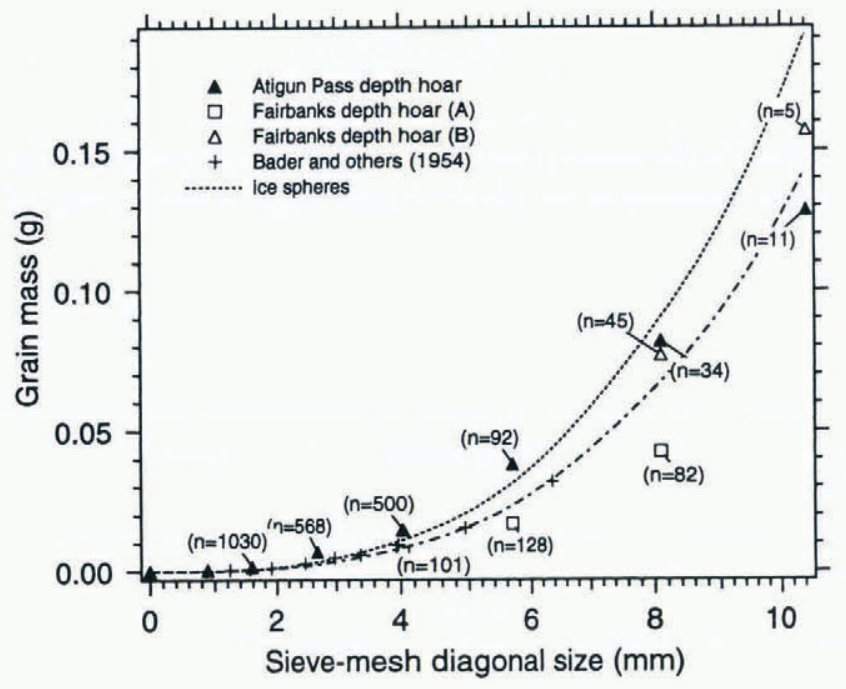

Fig. 3. Grain mass as a function of sieve size. $n$ is the number of samples that were weighed. Sieve size is customarily given as the length of the diagonal of the mesh openings. Data from Bader and others (1954) are included for comparison, and are surprisingly consistent given the radical differences in length of time the sieves were agitated (see text). A calculated curve (dotted) is shown for a hypothetical snow consisting of ice spheres.

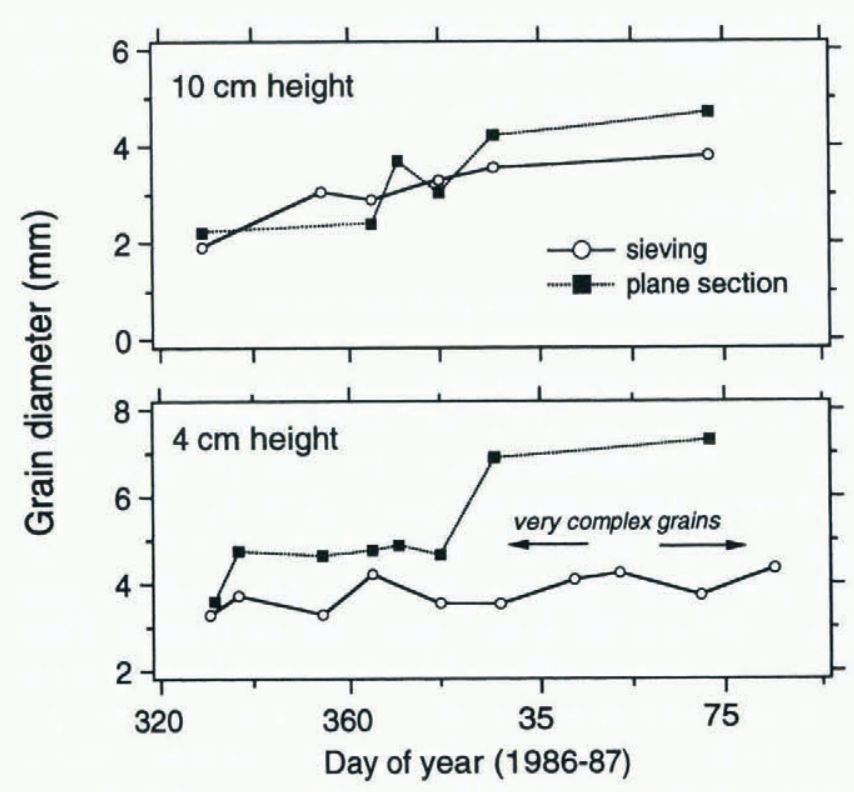

Fig. 4. A comparison of average grain-size determined by sieving with size determined by photographic methods for loose grains. The agreement is good at $10 \mathrm{~cm}$ height. At $4 \mathrm{~cm}$ height, the agreement is acceptable except for large, ornate grains.

photographs are compared in Figure 4. Sieve measurements tend to be biased toward smaller grain-sizes as a result of breakage of single grains. Stereological measurements tend to be biased toward larger grains because two touching grains may be digitized as a single larger grain. Dullien and Mehta (1972), working with salt grain-size distributions, found the same bias. In general, we observed differences to be less than $1 \mathrm{~mm}$. However, for snow that had metamorphosed into large, complicated grains, the agreement between the two methods was not as good. For these samples, differences in size arose because the large, ornate grains were poorly suited to being characterized by an equivalent circle or measured by sieving.

Metamorphosis of the snow into depth hoar was accompanied by a two- to three-fold increase in the grain-size. In Figure 5, the average size, determined by sieving and calculated using Equation (1), has been plotted for four layers of snow on the ground and two layers on the tables. At $4 \mathrm{~cm}$ height, and to a lesser extent for the other layers, some growth had already taken place before the first measurements were made, so the initial grain-size is not known. As suggested by the dotted lines in Figure 5, most grains were less than $1 \mathrm{~mm}$ in diameter at the start. They grew quickly after deposition, but growth rates soon decreased, as can be seen in the curves for the layers at 20 and $30 \mathrm{~cm}$. Grains in layers of snow on the tables, not subjected to strong temperature gradients, maintained nearly constant size during the same period that grains on the ground were growing.

As grain-size increased, the grain-size distributions changed (Fig. 6). The shift in the distribution curves indicates (a) the steady increase in the average grain-size, (b) the steady increase in standard deviation, evidenced by widening of the curves, and (c) a gradual shift from unimodal to bimodal then back to unimodal distributions. This evolution can be seen most clearly for the snow layers at 10 and $20 \mathrm{~cm}$, where a strong mode at $1.44 \mathrm{~mm}$ gradually disappeared while a second mode at $2.68 \mathrm{~mm}$ built, shifted 


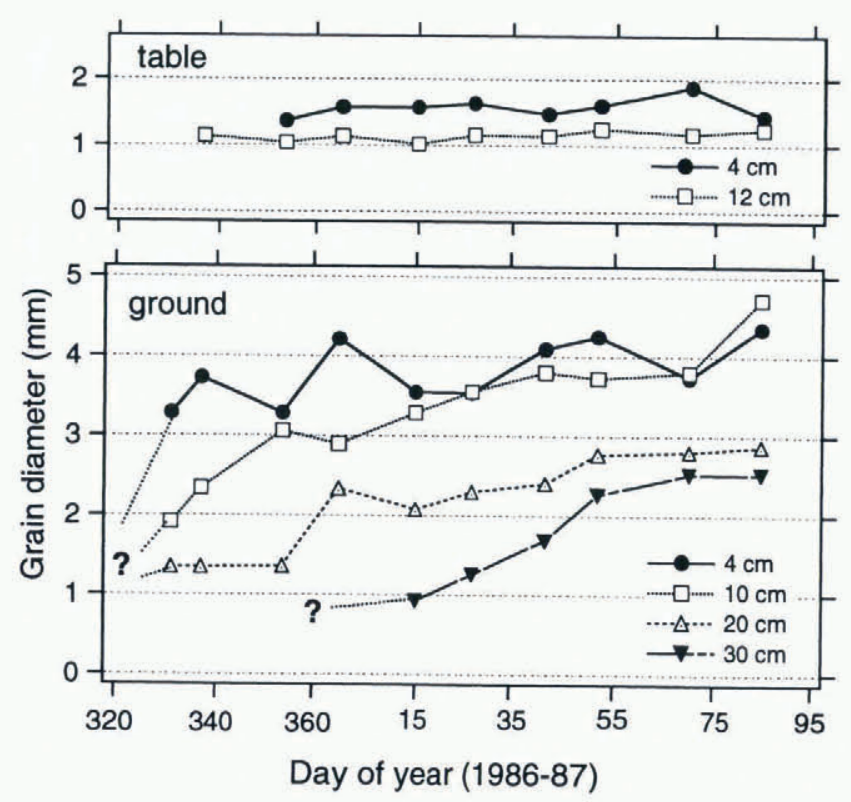

Fig. 5. The increase in mean grain diameter of four layers of snow on the ground and two layers on the tables during the winter of 1986-87. Some growth (indicated by dotted lines) had occurred before the first measurement. The initial size was about $1 \mathrm{~mm}$. Compare the lack of change in size for layers on the tables with layers on the ground.

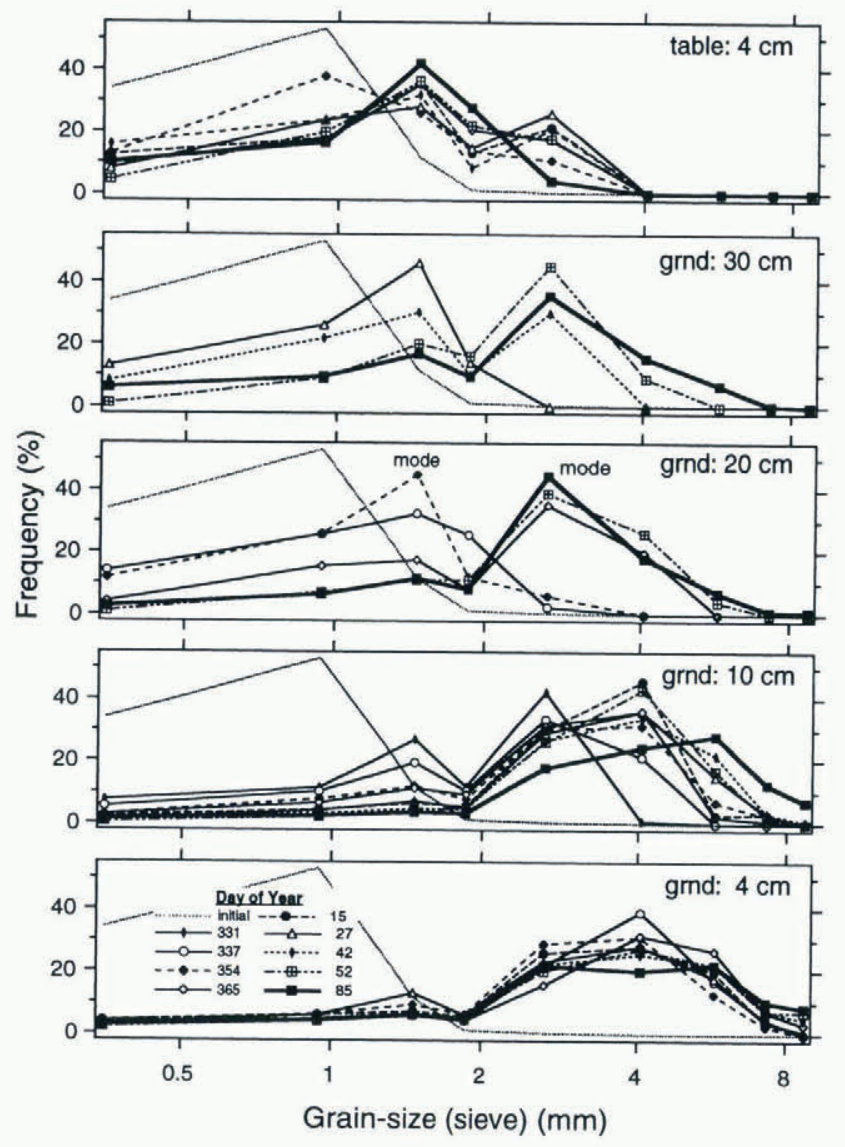

Fig. 6. Cumulative grain-size distribution curves for four layers on the ground and one layer on the tables. The snow at $4 \mathrm{~cm}$ had already metamorphosed into depth hoar before it was first sieved. A dotted line indicating the initial distribution has been added to each set for reference. Heavy solid lines are the final distribution of the winter. to the right and broadened as the snow metamorphosed into depth hoar. At $4 \mathrm{~cm}$ height, the layer was already depth hoar when it was first sieved, so its distribution curves remained constant throughout the winter. Again, the large changes observed for snow layers on the ground contrast sharply with the limited changes observed for layers on the tables.

The evolution of grain-size was accomplished through an order-of-magnitude decrease in the number of grains per unit mass (Fig. 7; Appendix A). Data from four layers of snow have been plotted as a function of time since deposition to highlight the trend. For these layers, most of the reduction in number occurred in the first few weeks. For example, the number of grains in the snow layer at $30 \mathrm{~cm}$ changed in the first $40 \mathrm{~d}$ from approximately $65 \times 10^{6}$ to less than $10 \times 10^{6}$ grains $\mathrm{kg}^{-1}$, but in the following $110 \mathrm{~d}$ the number of grains hardly changed at all. The decrease was accomplished by a drop in the number of small grains and a rise in the number of large grains. When first measured, there were no grains in the four largest sieves, but more than $50 \times 10^{6}$ grains $\mathrm{kg}^{-1}$ in the smallest sieve. By the end of the winter, the four largest sieves contained over $2 \times 10^{4}$ grains $\mathrm{kg}^{-1}$, all of them depth hoar, and the number in the smallest sieve had been reduced by a factor of 5 .

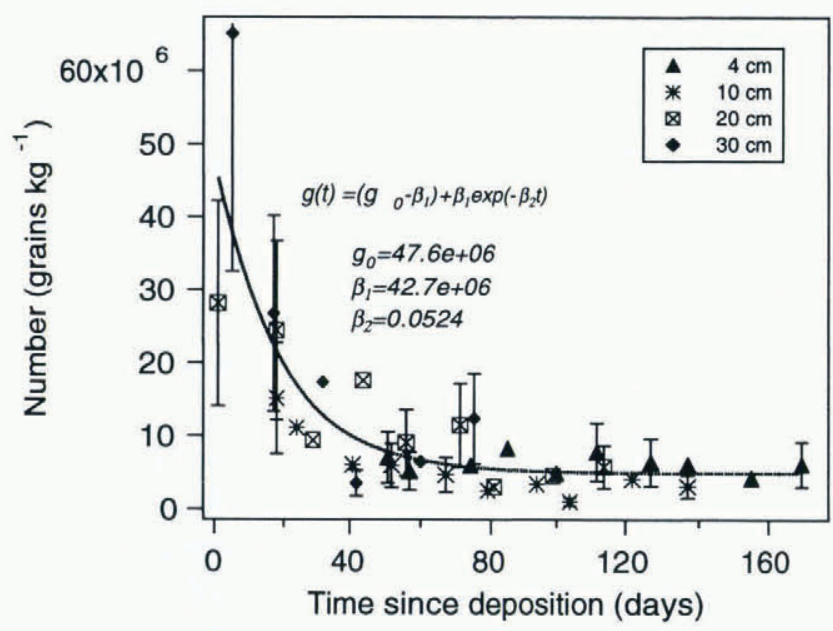

Fig. 7. The evolution of the number of snow grains (per unit mass) for snow layers at 4, 10, 20 and $30 \mathrm{~cm}$, winter of 1986-87.

The data in Figure 7 can be fit with an exponential curve:

$$
g(t)=\left(g_{0}-\beta_{1}\right)+\beta_{1} \mathrm{e}^{\left(-\beta_{2} t\right)}
$$

where $g$ is the number of grains per unit mass at time $t, g_{0}$ is the initial number of grains in the sample, $\approx 47.6 \times 10^{6} \mathrm{~kg}^{-1}$, and $\beta_{1}$ and $\beta_{2}$ are constants equal to $42.7 \times 10^{6}$, and 0.0524 , respectively, when time $(t)$ is measured in days. Though we do not use the results of Equation (3) directly, we present it here because the reduction in the number of snow grains during depth-hoar metamorphism has been noted by many observers (Paulcke, 1934; Seligman, 1936; Bader and others, 1954; Benson, 1962; Akitaya, 1974) but not previously quantified.

\section{Changes in density and layer thickness}

The end-of-winter density profile of the subarctic snowpack 


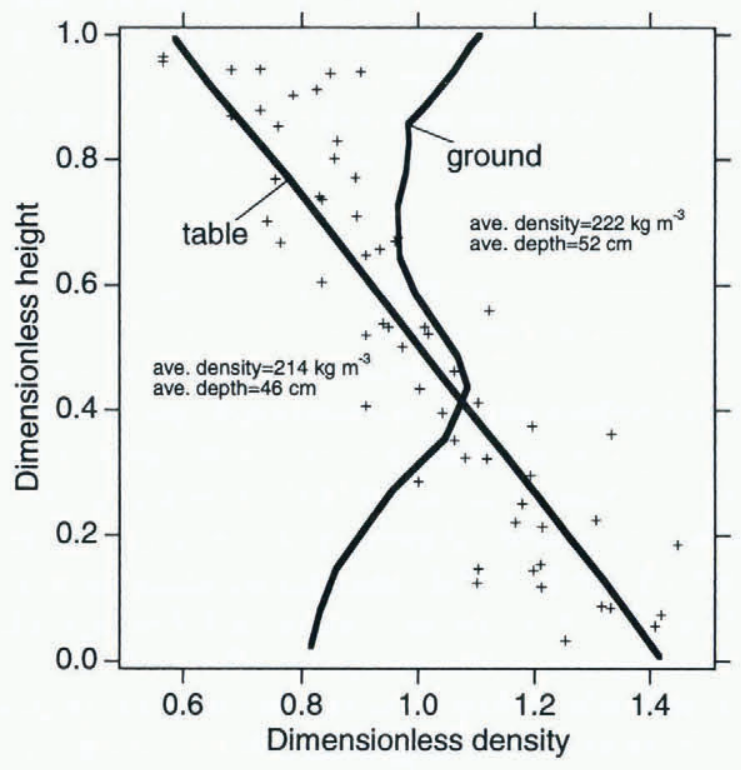

Fig. 8. Composite end-of-winter density profiles for snow on the ground and tables near Fairbanks, 1966-87. Snow on the tables was not subjected to strong temperature gradients, while snow on the ground was. The ground snow develops a profile that is nearly constant with height, while the table snow develops a profile that decreases with height. The profiles have been calculated from density profiles from 11 winters. Data for table snow are shown by the + symbols. Density profiles from the end of winter have been non-dimensionalized by dividing the snow depth $(h)$ and snow density $(\rho)$ by the total depth ( $h_{\text {total }}$ ) and the mean density ( $\left.\rho_{\text {ave }}\right)$. Using these nondimensional depth-density curves, the mean profile has been determined.

was usually uniform with height (Fig. 8). In contrast, the profile for snow on the tables showed a decrease in density with height (Fig. 8) more typical of snowpacks found in temperate climates. The contrast is due to differences in densification rates and in the way vapor transport redistributes mass in the pack. Layers on the ground densify more slowly than equivalent layers on the tables, while at the same time they lose mass due to an upward-directed vapor flux.
To illustrate, we note that all ten layers comprising the 1986-87 ground pack densified at a lower rate than the equivalent layers on the tables (Table 2; Fig. 9). On both table and ground, layers experienced an initial period of rapid densification followed by a secondary period of slower densification, but during both periods the ground snow densified more slowly than the table snow. In fact, during the secondary period, snow layers on the ground experienced little or no change in density, while equivalent layers on the tables continued to densify.

As the snow layers densified, they settled and compressed, leading to changes in thickness (Table 3; Fig. 10). Commensurate with changes in density, layers on the ground compressed more slowly than layers on the tables. Rates in the lowest layers on the ground ranged from 0.5 to $1.0 \mathrm{~mm} \mathrm{~d}^{-1}$, then decreased to less than $0.1 \mathrm{~mm} \mathrm{~d}^{-1}$ several weeks after the snow was deposited. Layers on the tables compressed at rates twice as fast, and continued to compress after layers on the ground had virtually ceased changing thickness. Basically, the depth hoar on the ground is more resistant to compaction than the fine-grained snow on the tables, a fact that has been noted by Kojima (1959), Akitaya (1974) and Armstrong (1985). This "stiffness" arises because the depth hoar forms vertical grain structures, described by Trabant and Benson (1972), Akitaya (1974),

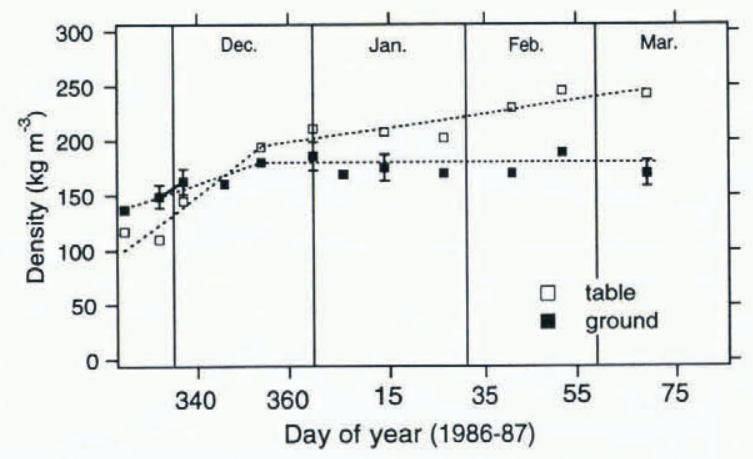

Fig. 9. Densification of snow layer 3 on the ground and the tables, showing typical rapid densification at first, and slower densification later.

Table 2. Density $\left(1 \mathrm{~kg} \mathrm{~m}^{-3}\right)$ of ten snow layers during the winter of 1986-87; layer thicknesses are given in Table 3

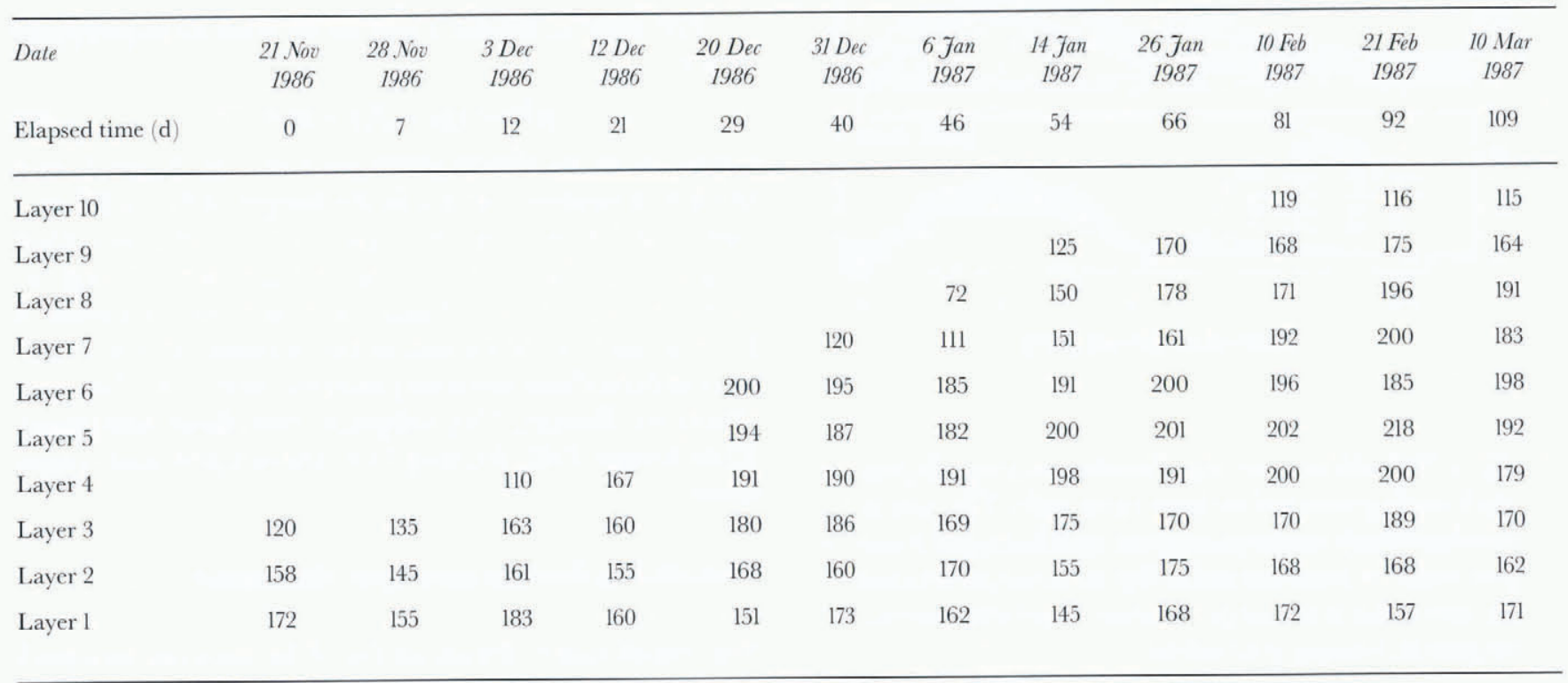


Table 3. Thicknesses (cm) of ten snow layers during the winter of 1986-87; densities are given in Table 2

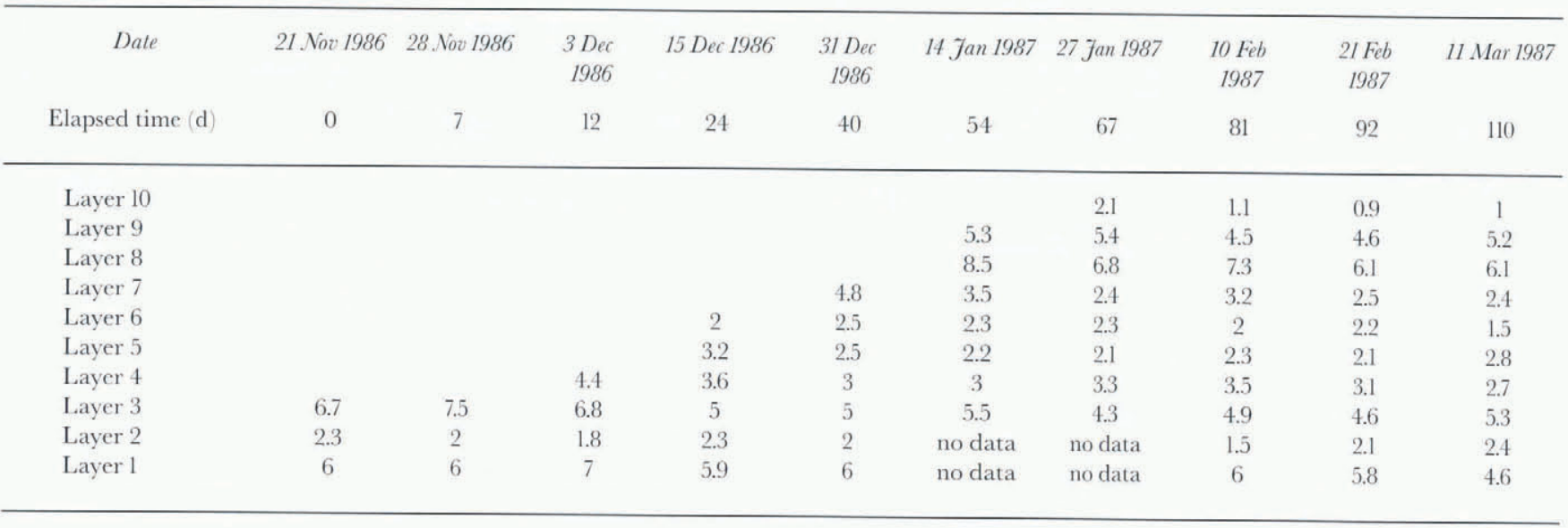

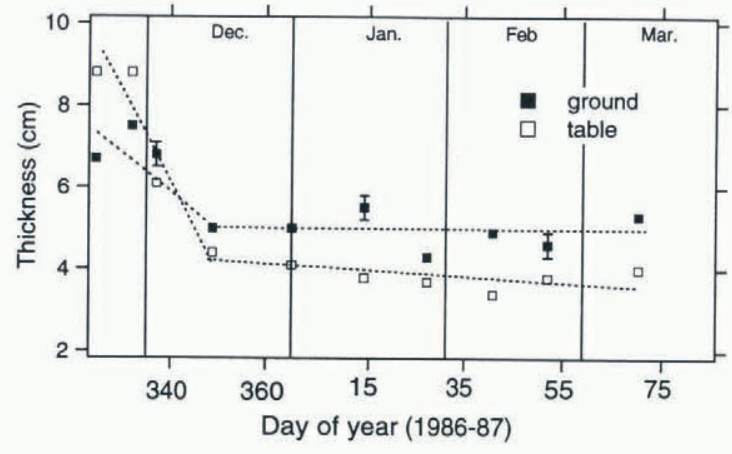

Fig. 10. Compaction of snow layer 3 on the ground and the tables, showing typical rapid compaction at first, and slower compaction later.

Colbeck (1986) and Sturm (1989, 1991), that function as stiff but brittle columns.

\section{Vertical temperature profiles in the snow}

Vertical temperature profiles in the subarctic snowpack show strong concave-downward curvature (Fig. 11), a fact we have verified many times during the past 30 years (unpublished information from C. S. Benson, 1972; Sturm, 1989, 1991). From one winter to the next, despite substantial differences in weather, snow depth and stratigraphy, temperature profiles are similar. In a survey of over 12000 measured temperature profiles taken between 1987 and 1992, over $75 \%$ exhibited concave-downward curvature.

\section{Isotopes and the height of water-vapor mixing}

About $5 \%$ of the total snow water equivalent at the experimental location was derived from the upward flux of water vapor out of the soil. The flux averaged $2.6 \times 0^{-7} \mathrm{~kg} \mathrm{~m}^{-2} \mathrm{~s}^{-1}$ (Table 4), sufficient to deposit a layer of ice about $0.5 \mathrm{~cm}$ thick beneath an impermeable tarpaulin. Ice beneath the tarpaulin was enriched in deuterium and ${ }^{18} \mathrm{O}$, compared to normal winter snowfall, because it was derived from rainwater (Fried-

1 In general, it is possible to calculate only the net water vapor fluxes, not the gross fluxes. Net fluxes are calculated from differences between the initial and final mass of a snow grain or layer. Large, balanced fluxes can potentially exist yet give rise to no change in density.

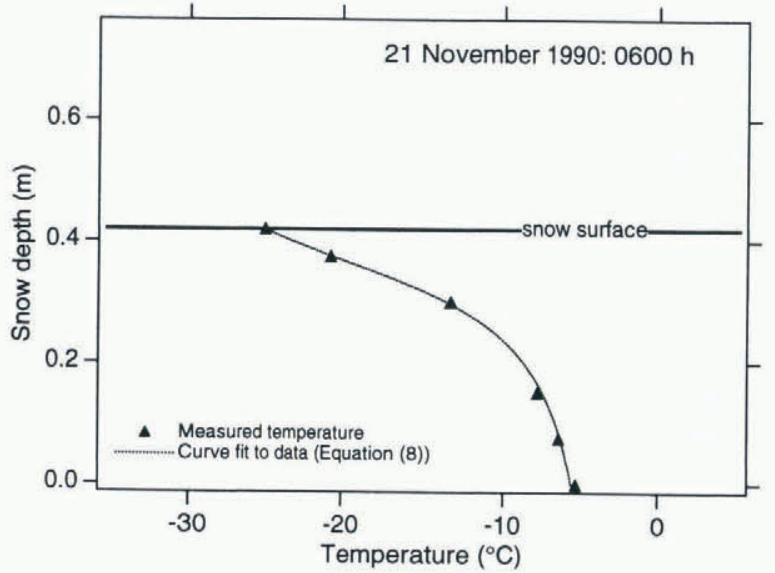

Fig. 11. A typical temperature profile from the subarctic snow showing strong concave-downward curvature.

man and others, 1991). This enrichment amounted to 40-50 per thousand $\delta \mathrm{D}$ when measured in 1975, 1985 and 1986 (Fig. 12). Where no tarpaulin was present, the water vapor from the soil entered the snowpack, enriching the basal layer of snow in deuterium and ${ }^{18} \mathrm{O}$. Based on ten sets of $\delta \mathrm{D}$ profiles taken between 1966 and 1987, this basal enrichment ranged from 19 to 30 per thousand $\delta \mathrm{D}$ when compared to equivalent snow layers on the tables (Fig. 12). The enrichment extended up through 10 $\mathrm{cm}$ in the snow, corresponding roughly with the M5 layer (Fig. 2).

We have calculated the isotopic composition of the basal

Table 4. Upward-directed soil water-vapor flux

\begin{tabular}{cc}
\hline Year & $\begin{array}{c}\text { Flux } \\
\mathrm{kg} \mathrm{m}^{-2} \mathrm{~s}^{-1}\end{array}$ \\
\hline $1967-68^{*}$ & $3.2 \times 10^{-7}$ \\
$1968-69^{* *}$ & $2.8 \times 10^{-7}$ \\
$1969-70^{*}$ & $3.5 \times 10^{-7}$ \\
$1973-74^{+}$ & $1.7 \times 10^{7}$ \\
$1985-86$ & $1.8 \times 10^{-7}$ \\
$1986-87$ & $2.6 \times 10^{-7}$ \\
Average & $2.6 \times 10^{-7}$
\end{tabular}

\footnotetext{
* Trabant and Benson (1972.

† C. S. Benson, unpublished (1974).
} 


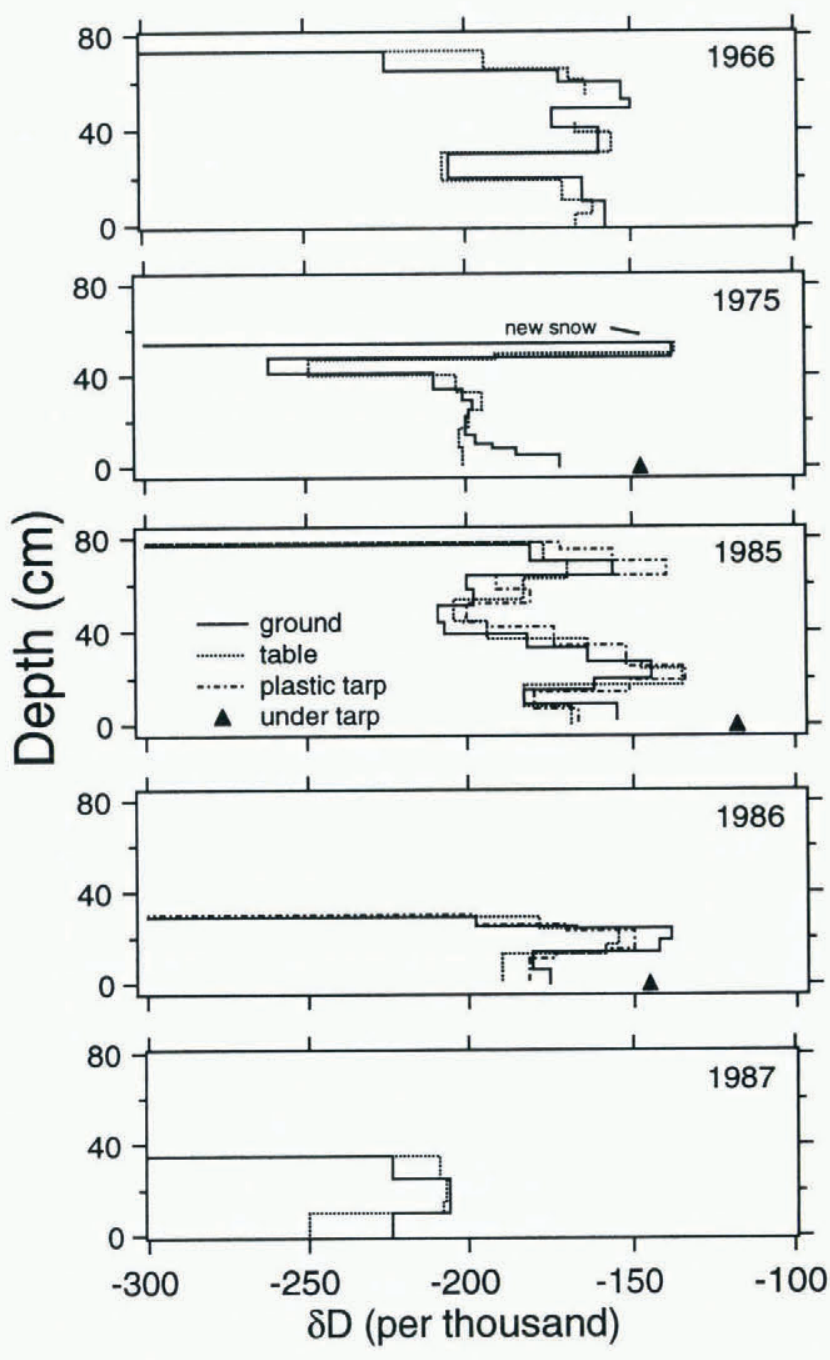

Fig. 12. Profiles of $\delta D$ values (per thousand) for snow on the tables, bare ground and a tarpaulin on the ground. Note that the basal $10 \mathrm{~cm}$ of snow on the ground is consistently heavier than the equivalent layer on the tables, while the opposite is true for the top $10 \mathrm{~cm}$.

layer of the snowpack for the hypothetical case where soil moisture was simply mixed into the layer. This was done by adding the mass of soil moisture (listed in Table 4), times the measured $\delta \mathrm{D}$ values of that moisture, to the product of the initial snow mass times its measured $\delta \mathrm{D}$ value. For the years for which we have data, mixing gives calculated $\delta \mathrm{D}$ values of $-193 \mathrm{vs}-184$ (measured) for 1975 ; -164 vs -155 for 1985; and -180 vs -177 for 1986 . In all cases, the measured value is "heavier" (depleted in lighter isotopes) than the value calculated by mixing. For 1985 and 1986, we can also calculate the $\delta^{18} \mathrm{O}$ values for the case of simple mixing and compare them to the measured values. These are plotted in Figure 13. Both measured $\delta \mathrm{D}$ and $\delta^{18} \mathrm{O}$ values are "heavier" than the hypothetical values due to mixing alone. We conclude, as did Friedman and others (1991), that while mixing is important, it is not the only process affecting the isotopic composition of the basal layers of snow. The slope of the lines connecting the isotopic compositions calculated for pure mixing to the measured compositions (Fig. 13) suggests that isotopic fractionation during sublimation and diffusion was also operating.

The snow on the ground, but above the impermeable tarpaulin, also showed a slight basal enrichment in $\delta \mathrm{D}$

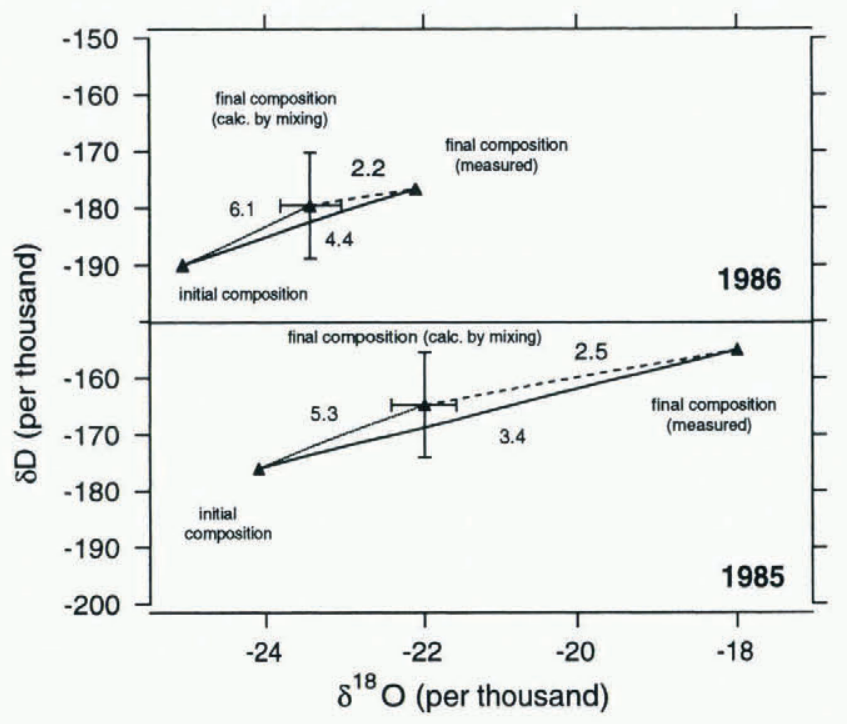

Fig. 13. Isotope trajectories for basal snow samples, 1985 and 1986. Numbers indicate the slope of the trajectories.

(Fig. 12). This could not have been the result of the migration of soil moisture into the snow, so it must have been due to the preferential removal of water vapor enriched in light isotopes. It confirms our conclusion that the final isotopic composition of the basal snow layer was the result of two processes: enrichment due to the migration of "heavy" soil moisture into the layer, and fractionation of vapor within the layer, resulting in the loss of "light" vapor upward under the influence of temperature gradients.

The "light" vapor appears to have traveled up to the top of the pack where some or all of it condensed. A consistent feature observed from 1966 to 1987 was a $5-20 \mathrm{~cm}$ thick layer at the top of the pack that was enriched in light isotopes (hydrogen and ${ }^{16} \mathrm{O}$ ) (Fig. 12). The observed enrichment varied from 10 to 30 per thousand $\delta \mathrm{D}$. In 1975 , new snow had fallen just before the samples were collected, so the enriched zone was just below the new snow layer. We know of no mechanism in dry snow that could preferentially remove "heavy" isotopes at the top, so we conclude the isotopic shift was the result of deposition of light isotopes moving up from below.

\section{ANALYSIS}

\section{Estimate of layer-to-layer vapor transport}

The growth of large depth-hoar crystals (Figs 2 and 5) is proof of the existence of net water-vapor fluxes ${ }^{2}$ between snow grains. Gubler (1985) referred to these as "inter-particle vapor fluxes". Such local net fluxes do not require the movement of vapor from one snow layer to another, nor do they necessarily result in a change in layer density. Net fluxes between layers, on the other hand, change the layer density and cause grain growth or shrinkage.

${ }^{2}$ Rapid variation in air temperature affects the near-surface snow temperature and can alter the curvature of the top $10-15 \mathrm{~cm}$ of the temperature profile, either enhancing the concave-downward curvature (cooling) or reversing the curvature (warming) near the top. This near-surface effect can usually be detected. 
The existence of net layer-to-layer vapor fluxes has been questioned. Marbouty (1980) and Armstrong (1985) found that the mass of a layer of snow remained constant during the growth of faceted depth-hoar grains, suggesting that the net layer-to-layer transport was zero. Trabant and Benson (1972), working in snow subjected to stronger temperature gradients for longer periods of time, found measurable amounts of mass transferred from one layer to another. Alley and others (1990), using measurements of snow density and the concentration of methanesulfonic acid in thin layers of near-surface snow undergoing depth-hoar metamorphism, also concluded that there was significant mass transfer. The present study, conducted at the same location used by Trabant and Benson, reaches the same conclusion.

The magnitude of the net layer-to-layer flux can be estimated by comparing end-of-winter density profiles from the ground and the tables (Fig. 8). Since the net layer-to-layer flux on the tables was negligible, we assume that any difference in the density profile on the ground compared to that on the tables is the result of a net upward transport of vapor on the ground. For ground snow, the loss of mass from the bottom of the pack was roughly equal to the gain at the top (Fig. 8). If in the course of a winter $(\approx 170 \mathrm{~d})$ the mass $\left(\approx 14 \mathrm{~kg} \mathrm{~m}^{-2}\right)$ moved up and none moved out of the top of the snow cover, it would require a net vapor flux of $9.5 \times 10^{-7} \mathrm{~kg} \mathrm{~m}^{-2} \mathrm{~s}^{-1}$. If this came from a lower layer $0.20 \mathrm{~m}$ thick, and went into an overlying layer $0.30 \mathrm{~m}$ thick (Fig. 8), the average vapor-flux gradient would have been $47.6 \times$ $10^{-7} \mathrm{~kg} \mathrm{~m}^{-2} \mathrm{~s}^{-1} \mathrm{~m}^{-1}$. This is an upper limit since it fails to account for the fact that snow on the tables compacts more rapidly than snow on the ground (Fig. 10), a point we return to later.

\section{Calculation of layer-to-layer vapor transport}

To calculate the net layer-to-layer flux, it is necessary to solve the continuity equation for a compacting layer of snow:

$$
\frac{\overline{\rho_{\mathrm{s}}}}{h} \frac{\partial h}{\partial t}+\frac{\partial \overline{\rho_{\mathrm{s}}}}{\partial t} \cong-\frac{\overline{\partial J_{\mathrm{v}}}}{\partial z}
$$

where $\overline{\rho_{\mathrm{s}}}$ is the layer density, $t$ is time, $h$ is layer thickness, $z$ is a vertical coordinate, and $J_{\mathrm{v}}$ is a vertical mass flux, here limited to water vapor. Both $J_{\mathrm{v}}$ and $z$ are positive upward, and the minus sign accounts for the fact that when more vapor enters through the bottom than exits through the top of the layer (a negative flux gradient) it increases the mass of the layer. The overbar denotes spatial averages across the layer.

We can solve Equation (4) using the density and thickness measurements made in 1986-87 (Tables 2 and 3), though large uncertainties in thickness $( \pm 3 \mathrm{~mm})$ and density $\left( \pm 14 \mathrm{~kg} \mathrm{~m}^{-3}\right)$ result in uncertainties in flux almost as large as the flux values themselves. Also, data from a crucial period between October and November, when the two basal layers of snow were probably experiencing vigorous vapor transport, are missing. Combined, the problems make our data insufficient to do a full seasonal vapor mass balance. However, they are sufficient to indicate the general time evolution of layer-to-layer fluxes in the snow, our main interest.

For each snow layer, linear compaction and densification curves of the form:

$$
\begin{aligned}
h(t) & =a t+b \\
\rho_{\mathrm{s}}(t) & =c t+d
\end{aligned}
$$

were fit to the data in Tables 3 and 4. Compaction and densification rates were relatively high immediately after a snow layer was deposited, but quickly dropped to lower rates (Figs 9 and 10), so the initial period of rapid change and the final period of slower change were fit separately. For initial and final line segments, derivatives were approximated by differentiating Equations (5) and (6). $\overline{\rho_{\mathrm{s}}}$ and $h$ were evaluated at the midpoint of each line segment, and Equation (4) was then solved, giving an early- and late-winter value of the vapor flux gradient. The results are listed in Table 5 ,

Table 5. Calculated layer-to-layer water flux gradients, net vapor fluxes and integrated fluxes, 1986-87

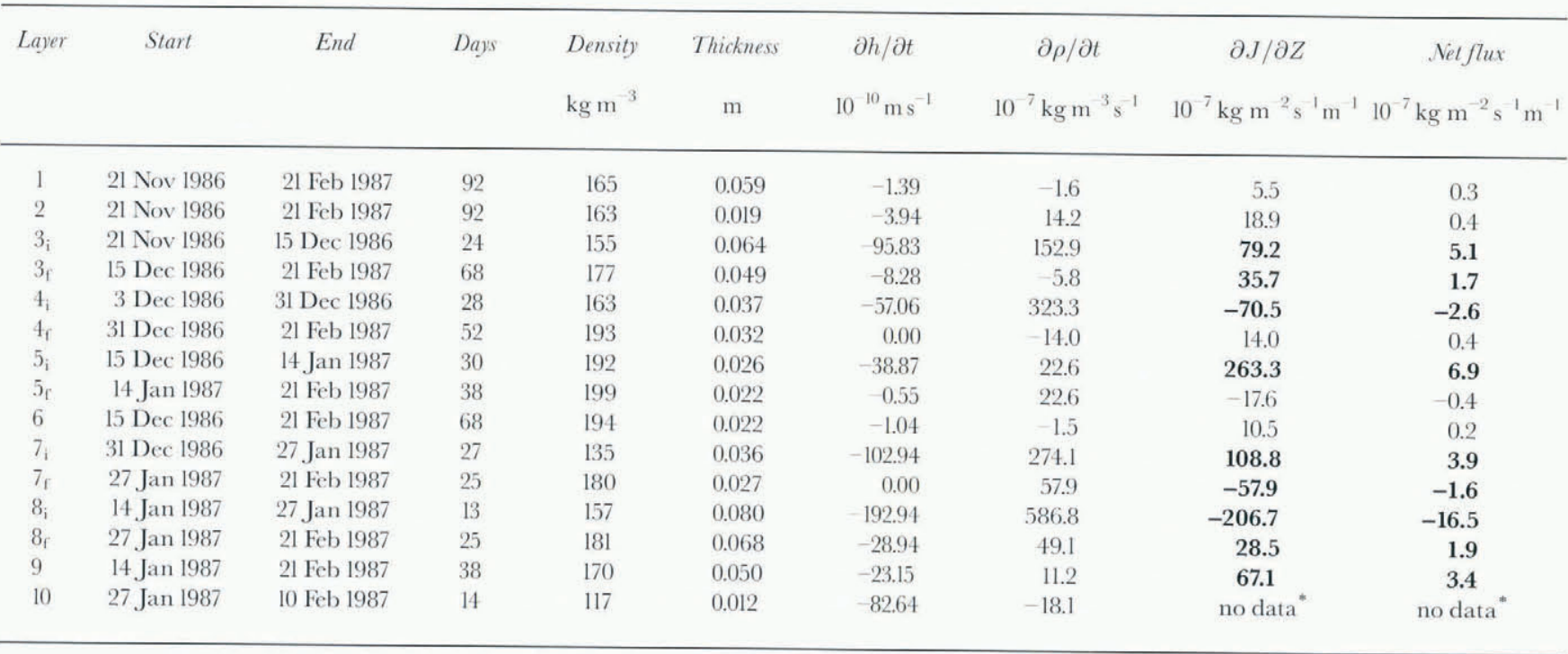

Bold-faced values are significant and not due to uncertainties in calculations.

Subscript "i", initial period of rapid compaction.

Subscript "f", final period of slower compaction.

* Top layer of snow difficult to work with: values unreliable. 
with subscript "i" referring to the initial and "f" to the final line segments. The results are also depicted graphically in Figure 14. The flux gradient was multiplied by the average layer thickness to determine the net flux from the layer (also in Table 5). Based on an error analysis (Appendix B), we list significant values in bold type. Initial values were not available for layers 1, 2 and 6, nor final values for layers 9 and 10 .

The mass redistribution took place in a complex and episodic manner. Peak flux gradients, generally observed immediately after a layer was deposited, were an order of magnitude greater than average values. These peak values, however, were maintained for relatively short periods of time, suggesting that much of the mass redistribution in the snow took place in short, intense bursts.

A more puzzling result was that the snow layers that gained mass ( + in Fig. 14) were not always near the surface of the snow. Stable-isotope data indicate an accumulation of vapor in the upper layers of snow (Fig. 12), and these layers are preferential sites for condensation of water vapor because they are colder than the snow lower in the pack (Nyberg, 1938). Condensation of vapor from the air results in the development of surface hoar (Lang and others, 1985; Colbeck, 1988). We expected that condensation of vapor moving up from the base of the pack would result in increased mass just below the surface. Instead, the calculations indicate that the mass often increased deeper in the pack. The coarse time resolution (two values per winter for each layer) make it possible that near-surface layers accumulated vapor when they were at the surface, but lost vapor later, when they were buried by new snow, thus ending in a net deficit over the period of calculation. It is also possible that we are mistaken in thinking the snow/air interface is the locus for vapor condensation.
Calculated flux gradients and net fluxes for the bottom two snow layers were relatively low (Table 5; Fig. 14), but the measured flux of vapor from the soil (Table 4) and the stable-isotope data (Fig. 12) suggest that these layers should have experienced some of the highest fluxes in the pack. They are the warmest layers, and are subjected to strong temperature gradients in early season (Fig. 1). The most likely explanation for the low values is that we missed a key period of high flux early in the winter just after the two layers were deposited. They had been on the ground nearly $40 \mathrm{~d}$ at the time that they were first measured in November 1986, and had already metamorphosed into depth hoar. This interpretation is even more plausible if we compare flux gradients and net fluxes based on measurements of individual layers (1986-87) with the values calculated from end-of-winter density profiles (1966-87; Table 6). The average flux gradient for $1986-87$ is about half the value calculated from a comparison of table and ground density profiles (Fig. 8), and the net flux in 1986-87 is about ten times lower. The values calculated from density-profile comparisons include early winter fluxes that are missing from the 1986-87 data set, and they agree with the values published by Trabant and Benson (1972) (Table 6).

For a true comparison, however, it is necessary to correct both our 1966-87 density profile values and those of Trabant and Benson (1972) for differential snow settlement on the tables and the ground. Both sets (Table 6) have been calculated without measuring changes in the thicknesses of snow layers. The calculations are based on two assumptions: (1) there is no net vapor flux in snow on the tables $\overline{\partial J_{\mathrm{v}}} / \partial Z$ in Equation (4) is zero), and (2) the compaction rate, $\left(\overline{\rho_{\mathrm{s}}} / h\right)(\partial h / \partial t)$, is the same on the tables as on the ground. Under these assumptions, the flux gradient on the ground

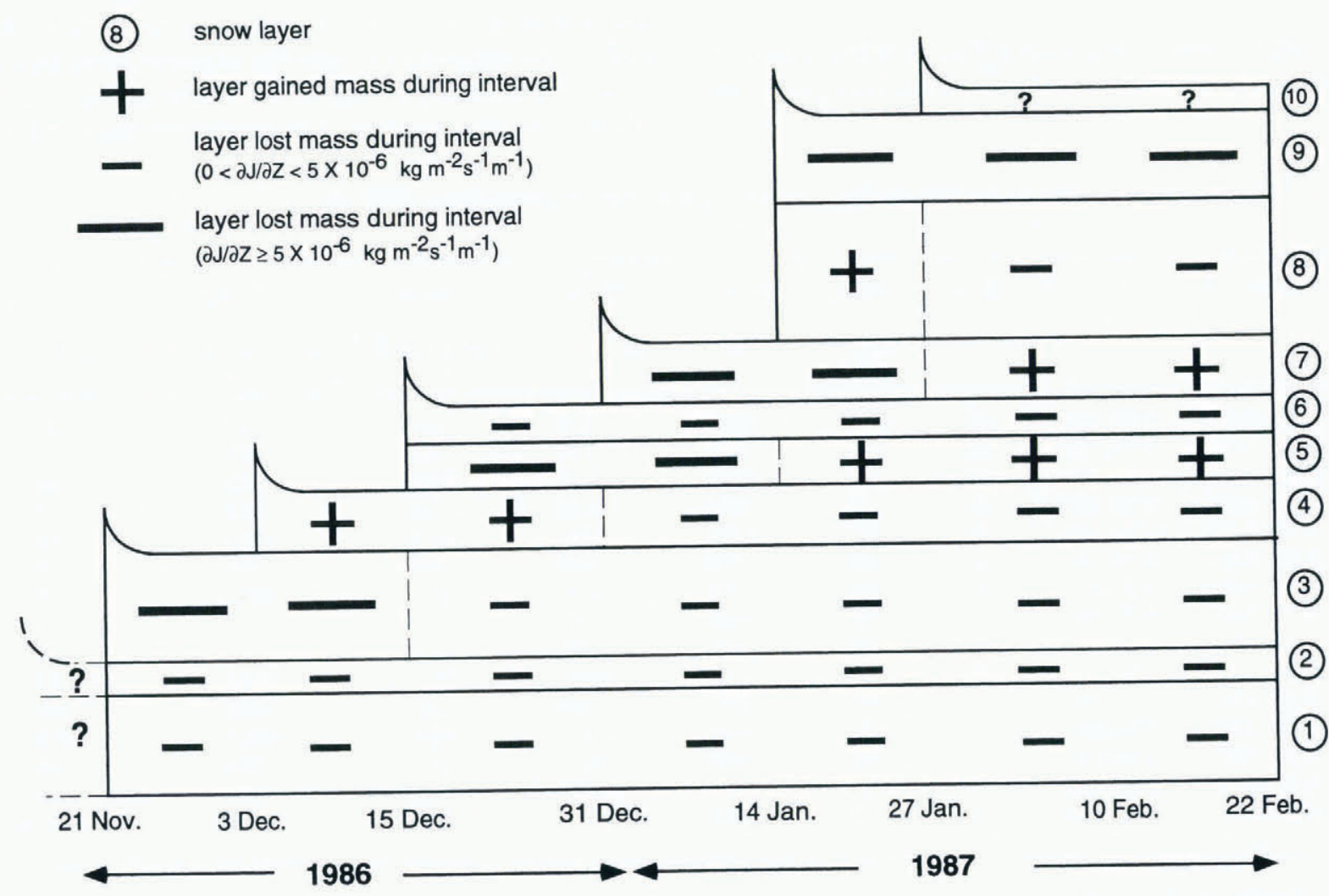

Fig. 14. Layer-to-layer vapor-flux gradients for the snowpack of 1986-87. Plus signs indicate a layer that was gaining mass, minus signs one that was losing mass. The size of the symbol (big or little) suggests if the rate was high or low. The vertical dashed lines in layers 3, 4, 5, 7 and 8 indicate the initial and final periods ( see Figs 9 and 10). 


\begin{tabular}{|c|c|c|c|c|}
\hline Source & $\begin{array}{l}\text { Flux gradient } \\
10^{-7} \mathrm{~kg} \mathrm{~m}^{-2} \mathrm{~s}^{-1} \mathrm{~m}^{-1} \\
\text { (uncorrected) }\end{array}$ & $\begin{array}{l}\text { Flux gradient } \\
10^{-7} \mathrm{~kg} \mathrm{~m}^{-2} \mathrm{~s}^{-1} \mathrm{~m}^{-1} \\
\text { (corrected) }\end{array}$ & $\begin{array}{l}\text { Net flux } \\
10^{-7} \mathrm{~kg} \mathrm{~m}^{-2} \mathrm{~s}^{-1} \\
(\text { uncorrected) }\end{array}$ & $\begin{array}{l}\text { Net Flux } \\
10^{7} \mathrm{~kg} \mathrm{~m}^{2} \mathrm{~s}^{-1} \\
(\text { corrected) }\end{array}$ \\
\hline Table and ground density profiles, 1966-87 (Fig. 8)" & 47.6 & 37.6 & 9.5 & 7.5 \\
\hline $\begin{array}{l}\text { Trabant and Benson }(1972)^{\dagger} \\
\text { Basal hoar, 1965-66 } \\
\text { Basal hoar, 1965-69 }\end{array}$ & $\begin{array}{l}53.2 \\
74.4\end{array}$ & $\begin{array}{l}43.2 \\
64.4\end{array}$ & $\begin{array}{l}6.9 \\
9.7\end{array}$ & $\begin{array}{l}5.6 \\
8.4\end{array}$ \\
\hline $\begin{array}{l}\text { Average, ten layers, } 1986-87 \text { (Table } 5)^{\ddagger} \\
\text { Peak }\end{array}$ & $\begin{array}{r}26.2 \\
263.3\end{array}$ & $\begin{array}{r}27.2 \\
263.3\end{array}$ & $\begin{array}{r}1.2 \\
16.5\end{array}$ & $\begin{array}{r}1.2 \\
16.5\end{array}$ \\
\hline $\begin{array}{l}\text { Average calculation from model using temporal } \\
\text { profiles, 1987, 1991, } 1992\end{array}$ & 50.0 & 50.0 & 2.5 & 2.5 \\
\hline Peak & 500.0 & 500.0 & 15.0 & 15.0 \\
\hline
\end{tabular}

Uncorrected indicates that differential compaction between tables and ground snow has not been accounted for.

Corrected by subtracting $10 \times 10^{-7} \mathrm{~kg} \mathrm{~m}^{-2} \mathrm{~s}^{-1} \mathrm{~m}^{-1}$ (the difference between table and ground compaction rates).

* Based on 11 table and ground density-profile comparisons, 1966-87.

+ Based on comparisons of densification rates on table and ground. Most reliable data for basal layers (C. S. Benson, personal communication, 1995).

¥ Based on data in Table 5. Values are spatial and temporal averages of flux gradient and net flux magnitudes.

can be evaluated by subtracting the densification rate for snow on the tables from the densification rate for snow on the ground. Unfortunately, the second assumption is wrong. Figure 10 shows that for stratigraphically equivalent layers, the layer on the table compacts more quickly than the layer on the ground, particularly immediately after deposition. Later in the winter the compaction rates are more nearly equal. In 1986-87, the difference between table and ground compaction term averaged $1.2 \times 10^{-6} \mathrm{~kg} \mathrm{~m}^{-3} \mathrm{~s}^{-1}$. Using this value, we have corrected the flux gradient and net flux values in Table 6 . Even with the correction, flux gradients computed from the snow-layer data of 1986-87 are still $50 \%$ lower than the flux gradients computed from density profiles for 1966-87. If we assume that flux gradients for the $40 \mathrm{~d}$ period at the beginning of winter missing from the 1986-87 data were approximately equal to the maximum observed flux gradient $\left(\geq 200 \times 10^{7} \mathrm{~kg} \mathrm{~m}^{-2} \mathrm{~s}^{-1} \mathrm{~m}^{-1}\right)$, then the recalculated values for $1986-87$ are consistent with the values computed from other data. Given that flux measurements cannot be made with great accuracy, we consider the agreement between the two methods quite good. Also, despite missing the flux from the two basal layers in 1986 87, the data for higher layers are still valid and are useful for showing the magnitude of the layer-to-layer fluxes and the complexity of the evolution of the layer-to-layer vaporflux system.

\section{A model of layer-to-layer vapor transport}

We now develop a simple model in order to examine the time-dependent transport of water vapor. It is a one-dimensional vapor-diffusion model, based on observed vertical temperature profiles in the snow, and the dependence of the equilibrium water-vapor density on temperature. The temperature profiles (Fig. 11), and the dependence of the water-vapor density on temperature, are both non-linear functions. In combination, they produce an equilibrium water-vapor density profile in the snow that has two inflection points. As a consequence, the model predicts that there will be a semi-stationary zone low in the pack where the snow density will decrease due to the loss of water vapor, and a complementary zone high in the pack where the density will increase due to the accumulation of vapor.

To run the model, we assume vertical heat and vapor flow. We further assume that the thermal conductivity is constant with height. In fact, thermal conductivity increases with height (Sturm and Johnson, 1992), which would result in vertical temperature profiles that had concave- upward curvature, if conductivity were the only variable. Because this is the opposite of what is normally observed (Fig. 11), our assumption of constant conductivity results in conservative estimates of vapor-flux gradients.

We also assume that the water-vapor density is in thermal equilibrium with the local snow and can be predicted by the Clapeyron equation, a common assumption (Bader and others, 1954; Colbeck, 1982). The equilibrium vapor density $\left(\rho_{\mathrm{v}}\right)$ is:

$$
\rho_{\mathrm{v}}=\rho_{\mathrm{v} 0} \mathrm{e}^{\left[L\left(T-T_{0}\right) /\left(R T T_{0}\right)\right]}
$$

where $T_{0}$ and $\rho_{\mathrm{v} 0}$ are the temperature and vapor density at the melting point $\left(0^{\circ} \mathrm{C}\right.$ and $\left.4.847 \mathrm{~g} \mathrm{~m}^{-3}\right), L$ is the latent heat of sublimation (2838 $\left.\mathrm{J} \mathrm{g}^{-1}\right), R$ is the gas constant for water vapor $\left(0.4619 \mathrm{~J} \mathrm{~g}^{-1} \mathrm{C}^{-1}\right)$, and $T$ is temperature (see Colbeck (1990) for the derivation of Equation (7)).

To each measured vertical temperature profile, we fit a smooth non-linear function of the form:

$$
T(z)=c_{0}+c_{1}\left[\frac{1}{\left(z-c_{2}\right)^{2}+c_{3}}\right]
$$

using a least-squares regression that minimizes the residuals. Equation (8) was chosen because it fits the data well, but otherwise has no physical significance. The fitting process is required to smooth the data in order to compensate for slight errors in temperature or the thermistor position. We substitute Equation (8) into Equation (7) to get a relationship between the equilibrium water-vapor density and height in the snow $\left(\rho_{\mathrm{v}}=\rho_{\mathrm{v}}(z)\right)$ for each temperature profile.

Next we assume that the vapor transport can be described by:

$$
J_{\mathrm{v}}=-F D_{0} \frac{\partial \rho_{\mathrm{v}}}{\partial z}+\phi \rho_{\mathrm{v}} \vec{v}
$$

where $J_{\mathrm{v}}$ is the water-vapor flux, $D_{0}$ is the water-vapor dif- 
fusion coefficient in air, $\phi$ is the porosity, $\vec{v}$ is the vertical convective velocity, and $F$ is an enhancement factor. Equation (9) is similar to Colbeck's (1982) equation (1). Sturm (1989, 1991) and Sturm and Johnson (1991) have shown that convection is common in the subarctic snow, so the second term on the right in Equation (9) may be important. But to simplify, we accommodate the convection in a heuristic fashion: we allow $F$, the enhancement factor, to increase if there is convection, but we remove the explicit convection term. Colbeck (1993) suggests $F$ ranges from 4 to 6 , but admits we know little about its true range of values. If convection were present it would be higher than 6 , and the magnitude of our flux gradients would increase. Since our main interest is the pattern of vapor transport, this simplification is unlikely to be severe.

Without an explicit term for convection, Equation (9) reduces to Fick's law. Differentiating with respect to height in the snow $(z)$ :

$$
\frac{\partial J_{\mathrm{v}}}{\partial z}=-D_{0}\left[\left(F \frac{\partial^{2} \rho_{\mathrm{v}}}{\partial z^{2}}\right)+\left(\frac{\partial \rho_{\mathrm{v}}}{\partial z} \frac{\partial F}{\partial z}\right)\right] .
$$

De Quervain (1973) derives a similar result.

We now assume that $F$ is constant with height. In reality, it probably varies. Colbeck's (1993) work suggests it should be a function of pore size in the snow. As shown in Figures 2 and 5, grain-size decreases with height, so pore size probably does too, and $F$ must vary. However, we have no data on how $F$ varies, so we leave it a constant. If it varied, it would change the magnitude but not the sense of our results.

Combining Equations (10) and (4), we get:

$$
\frac{\partial \rho_{\mathrm{s}}}{\partial t}=D_{0} F \frac{\partial^{2} \rho_{\mathrm{v}}}{\partial z^{2}}=-\frac{\partial J_{\mathrm{v}}}{\partial z}
$$

in which the flux gradient is given in terms of the second derivative of the water-vapor density, which can be approximated by numerically differentiating the combined Equations (7) and (8) twice, using a central difference scheme. Equation (11) also describes the rate at which a layer of snow will densify due to vapor condensation or sublimation, and we refer to it this way in our results.

Using Equations (7)-(11) and measured temperature profiles (taken every $6 \mathrm{~h}$ in $1986-87$ and every $1 \mathrm{~h}$ in $1989-$

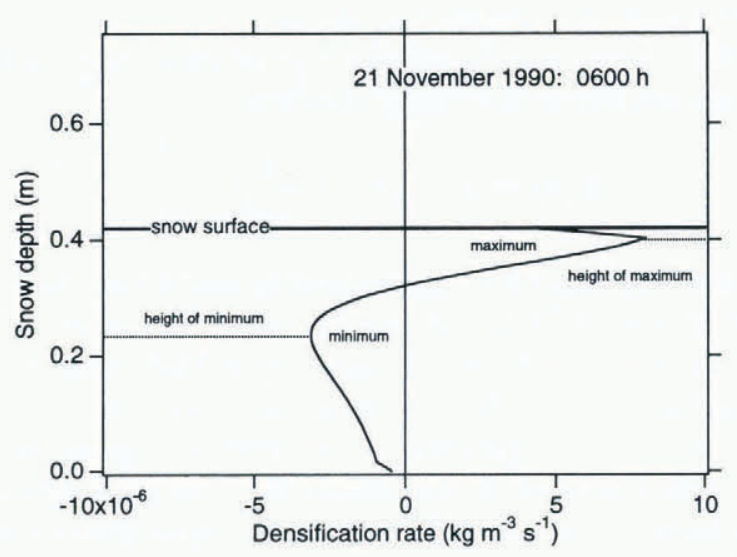

Fig. 15. The densification rate as a function of height ( see text for method of calculation), calculated for the temperature profile shown in Figure 11. The densification-rate maximum is just below the snow surface, and the minimum is about halfway between the base and the top of the snow.
90 and 1991-92), we have calculated the vapor-flux gradient (or densification rate resulting from vapor condensation) as a function of height in the snowpack. To illustrate the procedure, the temperature profile in Figure 11, typical of many profiles, has been fit with Equation (8). The densification-rate profile corresponding to the temperature profile, calculated using $F=4$, is shown in Figure 15. It has a minimum about one-third of the way up through the pack, and a maximum just below the top. These, respectively, are the locations of the most vigorous mass loss and gain. For each temperature profile, the same procedure was followed and the magnitudes of the maximum and minimum densification rates were recorded. They are plotted as a function of time in Figure 16. The height of the minimum (as a fraction of total depth) is also plotted; the height of the maximum is not shown since it was always slightly below the snow surface.

Densification rates were generally about $+50 \times 10^{-7}$ $\mathrm{kg} \mathrm{m}^{-2} \mathrm{~s}^{-1} \mathrm{~m}^{-1}$, though peak values ranged as high as $\pm 500 \times 10^{-7} \mathrm{~kg} \mathrm{~m}^{-2} \mathrm{~s}^{-1} \mathrm{~m}^{-1}$. This range of values is similar to that calculated from changes in snow-layer density (Table 6). Most peaks were transient spikes associated with rapid changes in air temperature. Maximum and minimum densification rates were coupled, but not identical. When the pack began to lose mass from the lower part at a high rate, it began to accumulate at a high rate in the upper part. In the model, we do not force the integrated value to be zero (i.e., our system is "open"), so these two rates do not have to be equal.

Several large events have been marked in Figure 16. All of these events occurred when the air temperature was low $\left(T_{\text {air }}<-25^{\circ} \mathrm{C}\right)$ and the snow relatively thin $(<30 \mathrm{~cm})$. The events have the same form: densification rates increase rapidly when the air temperature initially drops, but decay as the cold weather continues. Unlike the transient spikes, these events last several days and indicate an appreciable amount of transport. The events show marked differences in magnitude from one winter to the next. In 1986-87, one event had densification rates in excess of $500 \times 10^{-7} \mathrm{~kg} \mathrm{~m}^{-2} \mathrm{~s}^{-1} \mathrm{~m}^{-1}$ and lasted $10 \mathrm{~d}$. This occurred while the snow was less than $20 \mathrm{~cm}$ deep. In the other winters, the snowpack built up in the fall before the air temperature decreased, so calculated densification rates were about one-fifth of the magnitude observed in 1986-87.

The height of the minimum densification rate (top panels in Figure 16) tended to be low in the pack, particularly early in the winter when loss rates were highest. The result suggests that there would be a zone of net mass loss, potentially a weak layer, low in the snowpack. Its predicted location coincides nicely with the location of layer M4, which is noticeably weak (Fig. 4) and has textural features that suggest mass loss by sublimation. In 1989-90, the location of the minimum moved slowly but progressively higher in the snow during the season. Early in the winter when transport rates were highest, it tended to be located 20 $30 \%$ of the way up from the base of the snow. By the end of the winter it was $70-80 \%$ up from the base.

In summary, our temperature model predicts a vaportransport system that moves mass most vigorously from low (but not the base) to high in the pack. Vapor-flux gradients vary more than an order of magnitude, and are in the same range as those determined by other means (Table 6). The location of the minimum densification rate coincides with a notably weak layer. 

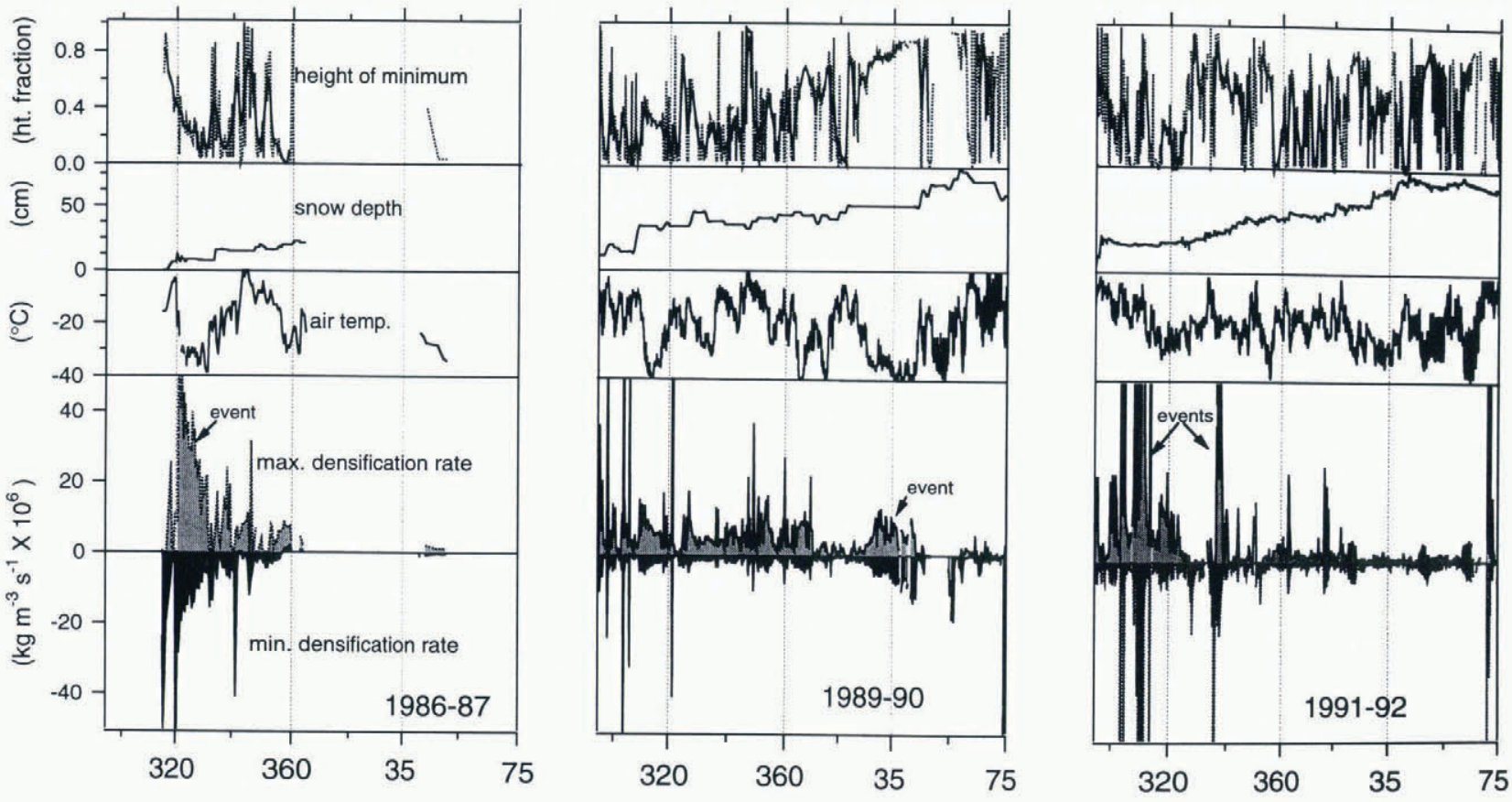

Day of Year

Fig. 16. The minimum and maximum densification rates (see Figs 11 and 15) for the winters of 1986-87, 1989-90 and $1991-92$. Air temperature and snow depth are shown for reference. Large flux events (high rates of densification) are marked. The fractional height (dotted line) of the flux-gradient minimum appears to rise from near the base to near the top of the snow as a function of time. A smoothed line (solid) has been drawn through the data to highlight the trend.

\section{Estimates of grain-to-grain vapor transport}

In 1986-87, about one out of ten grains grew, while the rest shrank (Fig. 7). If one assumes spherical grains and no layerto-layer vapor fluxes, this would yield an increase in size by a factor of 2-3, which is close to what was observed (Fig. 5). We can use these grain-growth measurements to estimate the net inter-particle flux.

First, we estimate the net inter-particle flux from photogrammetric measurements of the width, height and thickness of 70 grains photographed in March 1986. From these measurements, we calculate that the end-of-winter mass of individual grains varied from 1 to $8 \times 10^{-5} \mathrm{~kg}$. The grains began to grow in November 1985, at which time their mass was nearly an order of magnitude smaller. Subtracting the initial mass from the final mass and dividing by the elapsed time, the growth rates ranged from 1 to $11 \times 10^{-12} \mathrm{~kg} \mathrm{~s}^{-1}$. Dividing by the average surface area of an individual grain, estimated from the photographs, we calculate that the net inter-particle vapor flux averaged 0.24 to $0.90 \times 10^{-7} \mathrm{~kg} \mathrm{~m}^{-2} \mathrm{~s}^{-1}$ during the winter.

\section{Calculation of grain-to-grain vapor transport}

We can also use the changes in the average grain-size shown in Figure 5 to estimate the net inter-particle flux. The growth curves have been replotted as a function of the elapsed time since each layer was deposited (Fig. 17), with grain diameter replacing grain radius for convenience. Two distinct trajectories (grain radius vs time) are suggested by the data, one for the lower snow layers $(4$ and $10 \mathrm{~cm}$ ), and one for the upper snow layers $(20$ and $30 \mathrm{~cm}$ ). The lower layers were less dense than the upper layers and on average $5^{\circ} \mathrm{C}$ higher in temperature, two conditions conducive to more rapid growth.

The trajectories shown in Figure 17 are exponential curves:

$$
r(t)=r_{\infty}-\left(r_{\infty}-r_{0}\right) \exp (-\alpha t)
$$

where $r$ is the grain radius $(\mathrm{mm}), r_{0}$ is the initial radius, equal to $0.52 \mathrm{~mm}$ for both upper and lower layers, and $r_{\infty}$ is the radius a grain converges to with time. For the lower layers, $r_{\infty}=2.13 \mathrm{~mm}$ and $\alpha=0.0209$; for upper layers, $r_{\infty}=1.88 \mathrm{~mm}$ and $\alpha=0.0102$.

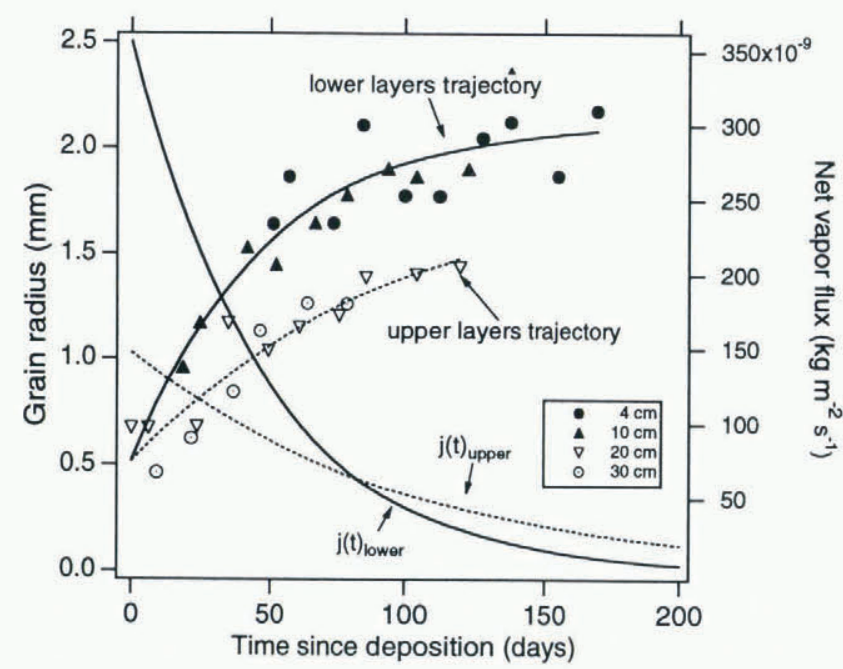

Fig. 17. Growth-rate curves for two upper and two lower layers of snow, 1986-87, with the net inter-particle vapor flux implied by this growth rate (see text for details) shown on the right axis. 
When differentiated, Equation (12) gives the growth rate:

$$
\frac{\mathrm{d} r}{\mathrm{~d} t}=\alpha\left(r_{\infty}-r_{0}\right) \exp (-\alpha t) .
$$

The exponential forms in Equations (12) and (13) indicate a growth rate $(\mathrm{d} r / \mathrm{d} t)$ proportional to the number of grains present in a layer at a given time (i.e. the number of vapor sources), and are consistent with Equation (3), which indicates that this number decays exponentially with time.

Equation (13) can be used with a simple model of spherical grains to estimate the net inter-particle vapor flux. Approximating snow grains as ice spheres is not that extreme an assumption given the similarity of the curve for spheres and the other curves in Figure 3. The model also requires the assumption that the rate of water-vapor condensation on a spherical grain is proportional to its surface area. Under these assumptions, the rate of change of mass of an average grain with time $(\mathrm{d} m / \mathrm{d} t)$ is:

$$
\frac{\mathrm{d} m}{\mathrm{~d} t}=4 \pi \rho_{\mathrm{i}} r^{2} \frac{\mathrm{d} r}{\mathrm{~d} t}
$$

where $\rho_{\mathrm{i}}$ is the density of ice, and we have made use of the relationship $\mathrm{d} V / \mathrm{d} t=(\partial V / \partial r)(\partial r / \partial t)$ between the volume $(V)$ and the radius to derive Equation (14). The rate of condensation of water vapor per unit area $(j(t))$ on a growing grain multiplied by the surface area of the grain $\left(S=4 \pi r^{2}\right)$ must equal the time rate of change of mass, thus:

$$
j(t)=\rho_{\mathrm{i}} \frac{\mathrm{d} r}{\mathrm{~d} t}=\rho_{\mathrm{i}} \alpha\left(r_{\infty}-r_{0}\right) \exp (-\alpha t) .
$$

Based on the data in Figure 17, the net condensation rate or net inter-particle flux rate, $j(t)$, was initially high, but then diminished, asymptotically approaching zero as the winter progressed. The warmer, more rapidly growing grains of the lower layers initially experienced net fluxes several times greater than those in the colder, upper layers of snow. The average values calculated with the model 0.52 and $0.68 \times 10^{-7} \mathrm{~kg} \mathrm{~m}^{-2} \mathrm{~s}^{-1}$ for upper and lower layers, respectively) are consistent with the average values estimated from photogrammetric measurements. These rates are for "average" grains. Actual fluxes must have varied widely.

\section{DISGUSSION}

We have shown that net layer-to-layer vapor fluxes exist in the subarctic snowpack using four independent methods: (1) end-of-winter density profiles, 1966-87 (Fig. 8); (2) density and layer-thickness measurements, 1986-87 (Fig. 14); (3) stable-isotope measurements, 1966-87 (Fig. 12); and (4) results from a model based on observed temperature profiles (Fig. 16). Isotope data indicate that transport distances for the vapor were equal to the snow depth, about $50 \mathrm{~cm}$ in our experiment.

The four methods agree, within a factor of 4 , on the magnitude of the net layer-to-layer flux (Table 6), and this agreement is closer if reasonable adjustments are made. It is good agreement given the difficulty of making the measurements. Our best reconciliation of all methods suggests that the average net layer-to-layer flux is $\pm 6 \times 10^{-7} \mathrm{~kg}$ $\mathrm{m}^{-2} \mathrm{~s}^{-1}$ (Table 6). Short-lived peak values are $\pm 50 \times 10^{-7}$ $\mathrm{kg} \mathrm{m}^{-2} \mathrm{~s}^{-1}$, eight times higher than average (Table 5; Fig. 16). As the values suggest, the net flux varies in an episodic manner, with brief bursts of high values. In 1986-87 the bursts were observed in early winter when the snow was thinnest and the temperature gradients strongest (Figs 1 and 16). Under those extreme conditions, a lot of vapor may have moved in a short period of time.

The data also demonstrate the existence of inter-particle fluxes. During the extreme depth-hoar metamorphism that takes place in the subarctic snowpack, one out of ten grains increases in size by a factor of 2-3 (Fig. 5), while the rest of the grains shrink and disappear in order to supply vapor to the growing grains (Figs 5 and 7). The observed growth rates imply an average inter-particle flux of 0.52 to $0.68 \times 10^{-7} \mathrm{~kg} \mathrm{~m}^{-2} \mathrm{~s}^{-1}$, with peak values about six times higher (Fig. 17) maintained only for short periods just after snow layers are deposited.

Comparing the average layer-to-layer and inter-particle flux values, we reach a key conclusion: net layer-to-layer fluxes are approximately ten times greater than net interparticle fluxes.

Several implications follow from this fact. First, the observed layer-to-layer net flux rates are unnecessary to maintain depth-hoar growth. The layer-to-layer rates could drop by an order of magnitude, and presumably the vapor supply to growing grains would still be sufficient to maintain steady growth. As a tangible demonstration of this fact, we note that the texture and grain-size of basal snow layers over an impermeable tarpaulin were indistinguishable from those of snow not over the tarpaulin, even though the tarpaulin blocked a substantial contribution of vapor from the soil (Table 4).

There was also no detectable difference in density profiles over the tarpaulin vs over the soil. This highlights the fact that the density changes induced by layer-to-layer fluxes are right at the limit of detectability. Any decrease in layer-to-layer flux would have resulted in changes in density too small to be measured and the conclusion that layer-tolayer fluxes were not present. We believe this is why both Marbouty (1980) and Armstrong (1985) observed distinct depth-hoar growth but concluded that there were no layerto-layer fluxes.

A second implication of the high ratio of layer-to-layer to inter-particle fluxes is that the limiting factor for depthhoar growth is not the rate at which vapor is being supplied to the growing grains. This is not a new finding, but is derived here in a new manner. Colbeck $(1983,1986)$, based on laboratory crystal-growth experiments and the literature, concluded that kinetic growth forms like depth hoar result from the dynamics of crystal growth rather than limitations in the rate at which vapor is supplied to the crystal. Our data, based on the mismatch between inter-particle and layer-to-layer flux measurements, support this conclusion.

Why, then, if the vapor supply stays high throughout the winter (Fig. 13; Table 5), does the grain-growth rate flatten out and the inter-particle flux rate drop precipitously, as shown in Figure 17? We speculate that the answer is contained in Figure 2, which illustrates how ornate and complicated the depth-hoar structure becomes over time. This geometric complexity could affect the growth rate in three ways. Grains could grow so large as to lose thermal efficiency in cooling, thereby becoming progressively less efficient for growth, and more efficient for loss by sublimation. Gubler (1985) proposed an idea such as this in his graingrowth model. Alternately, the amount of vapor bypassing grains and moving to higher layers in the snow could in- 
crease, decreasing the growth rate. Finally, the growth could be space-limited, with growth rates diminishing when growing grains begin to interfere with each other. However, observations suggest that individual grains have more space and interfere less as depth hoar develops, so we rule out this last mechanism as a control immediately.

There seems to be no intrinsic limit on the size of kinetic crystal forms like depth hoar. Koch and Wegener (1930), Knight and De Vries (1985) and M. Sturm (unpublished information, 1987, 1995) have all described individual crevasse or ice-cave hoar crystals up to $15 \mathrm{~cm}$ in length. In Fairbanks, surface hoar can grow to $4 \mathrm{~cm}$ in length over several clear nights. In contrast, the largest depth-hoar grains we have observed are about $3 \mathrm{~cm}$ in length, and they are the result of months of growth. A key element in the growth of large surface and cave hoar is rapid air convection. Colbeck (1988) indicates that air speeds up to $1 \mathrm{~ms}^{-1}$ may be involved in their growth. If air convects in the snowpack, flow rates are closer to $0.2-2 \mathrm{~mm} \mathrm{~s}^{-1}$ (Sturm, 1989, 1991). This mismatch in convective speeds makes it unlikely that depth-hoar growth requires air convection and, further, that somehow, as the season progresses, changes in the convective flow cause more vapor to bypass grains. However, we cannot completely discard the idea, because depth-hoar grains become so deep, skeletal and hollow that supplying water vapor to the enclosed spaces may be difficult.

Scrutiny of the depth-hoar sequence illustrated in Figure 2 and the growth rates shown in Figure 17 suggests that thermal control may be the best explanation. Depth-hoar grains reach a maximum size part-way through the winter, yet their form continues to change. Initially the predominant forms are downward-facing hexagonal cups. These become larger, more ornate and deeper with time, eventually becoming almost as large as the prisms found in the lower layers of the pack (compare M3 to M4 and M5; Table 1). The growth rates (Fig. 17) flatten out before the more advanced depth-hoar forms of M4 and M5 are realized. Thus, the transformation from M3 to M4 and M5 textures takes place at nearly constant size, indicating that rates of mass loss and gain by sublimation are nearly balanced. This interpretation suggests thermal control as the limiting factor on depth-hoar size, with grains reaching a size sufficient to make them sites of both gain and loss at the same time.

One other key result from this study is an explanation for the weak layer (M4 in Fig. 2) near but not at the base of the snow. The M4 layer has striking textural features associated with high rates of mass loss by sublimation and reduced grain bonds. Our temperature-profile model predicts a semi-stationary zone of high vapor loss at about the same height. Such a zone would lead to the development of a weak layer with sublimation features like those observed. The zone arises as a direct consequence of the non-linear temperature profiles interacting with the highly non-linear vapor-density dependency with temperature. Similarly curved profiles are commonly observed in the alpine snowpacks of Colorado and Montana, U.S.A., and in these locations there have also been indications of avalanches running on a depth-hoar layer near but not at the base of the snow packs. Perhaps the avalanches are triggered by disruption of a layer similar to the weak M4 layer.

Lastly, do our data allow us to evaluate the hand-tohand model of Yosida (1955)? Not directly. We cannot tell from our data if the layer-to-layer transport is achieved through a series of small hops by water molecules, moving from one grain to another, or by longer-distance transport. The observations that almost all depth-hoar grains have growth features on the bottom and erosion features on top supports the hand-to-hand concept. On the other hand, the fact that the net layer-to-layer flux rates are so much higher than the inter-particle flux rates could indicate excess water vapor by passing grains. However, grain growth limited by a thermal control, not vapor supply, as discussed above, seems more likely, and supports the "hand-to-hand" process.

Our study indicates that grains gain and lose water molecules at a rate many times higher than the rate at which they grow. It explains why the grains can so readily metamorphose, even if they do not change size. The molecules comprising an individual grain go into the vapor state and back to the solid state many times over during the winter. Basically, a growing grain in the subarctic snowpack is in near-equilibrium throughout the winter but has a high rate of mass exchange and a high potential for metamorphism.

\section{CONCLUSIONS}

The subarctic snowpack near Fairbanks, Alaska, metamorphoses completely into depth hoar by the end of the winter. The depth hoar evolves through a sequence of five textures, producing a layered structure including a layer near (but not at) the base of the snow, which is poorly bonded, has obvious sublimation features, and is notably weak. Sieve measurements indicate that during the transformation into depth hoar, the mean grain-size increases by a factor of 2-3, while the number of grains per unit mass decreases by a factor of 10 . Growth rates are initially high, but then decrease, approaching zero by the end of the winter.

Calculations indicate that the observed growth rates require an inter-particle flux rate of $0.6 \times 10^{-7} \mathrm{~kg} \mathrm{~m}^{-2} \mathrm{~s}^{-1}$. Net layer-to-layer vapor fluxes from the base to the top of the snowpack are an order of magnitude higher, with peak values two orders higher. Detailed measurements made in 1986-87 show that the layer-to-layer vapor transport takes place in an episodic manner, with the net flux varying with time and position in the snowpack. Peak fluxes are observed early in the winter and just after layers are deposited. Snow layers just above the base of the snow tend to be preferential sites for high rates of mass loss, while layers near the surface tend to be sites of mass gain. The existence of this base-totop transport system is confirmed by stable-isotope data.

A model based on observed temperature profiles and diffusive vapor transport predicts a bottom-to-top layer-tolayer vapor-flux system similar to the one indicated by density and isotope measurements. The model also correctly predicts the development of a weak layer near the base of the snow.

From the study, we observe that net layer-to-layer vaportransport fluxes are ten times higher than the net inter-particle fluxes. This accounts for kinetic grain growth and depth-hoar formation being observed in snow covers where changes in layer density could not be detected. It also suggests that the decrease in grain-growth rates observed by the middle of winter is not the result of decreasing vapor supply, but rather of some other mechanism, most likely a thermal control resulting from changes in grain-size and form. The $10: 1$ ratio of fluxes also suggests that rates of mass 
loss and gain for individual grains are many times higher than the growth rate of the grains. With such high rates of vapor exchange, the growing grains can be thought of as being in near-equilibrium throughout the winter, and therefore readily able to metamorphose even while their size remains constant.

\section{ACKNOWLEDGEMENTS}

We thank the following people for their help in the field, in collecting data, or in clarifying our thinking on depth-hoar growth: J. Johnson, W. Harrison, E. Chacho, B. Sturm, D. Trabant, M. Stark, J. Holty and J. Kelly. I. Friedman has been an invaluable colleague in the analysis and interpretation of the stable isotopes. S. Colbeck and E. Arons provided insightful review comments that have greatly improved the paper. The work was initiated with a grant from Dr T. Moore, second president of the University of Alaska, and supported by U.S. Army contract 4A762784-AT42-SS-E07, U.S. National Science Foundation grants OPP-94-15386, G-22224, DPP79-26425 and DPP9002345, and U.S. Department of Energy grant DE-RG-06-84ER60245.

\section{REFERENGES}

Akitaya, E. 1974. Studies on depth hoar. Contrib. Inst. Low Temp. Sci., Ser. A 26. Alley, R. B., E. S. Saltzman, K. M. Cuffey and J.J. Fitzpatrick. 1990. Summertime formation of depth hoar in central Greenland. Geophys. Res. Lett., 17 (12), 2393-2396.

Armstrong, R. L. 1985. Metamorphism in a subfreezing, seasonal snow cover: the role of thermal and vapor conditions. (Ph.D. thesis, University of Colorado.

Bader, H., R. Haefeli, E. Bucher, J. Neher, O. Eckel and C. Thams. 1954. Snow and its metamorphism. SIPRE Transl. 14.

Benson, C. S. 1962. Stratigraphic studies in the snow and firn of the Greenland ice sheet. SIPRE Res. Rep. 70.

Blatt, H., G. Middleton and R. Murray. 1972. Origin of sedimentary rocks. Englewood Cliffs, NJ, Prentice-Hall Inc.

Carroll, T. 1977. A comparison of the CRREL $500 \mathrm{~cm}^{3}$ tube and the ILTS 200 and $100 \mathrm{~cm}^{3}$ box cutters used for determining snow densities. F. Glaciol., 18 (79), 334-337.

Colbeck, S. C. 1982. Growth of faceted crystals in a snow cover. CRREL Rep. 82-29.

Colbeck, S. C. 1983. Ice crystal morphology and growth rates at low supersaturations and high temperatures. F. Appl. Phys, 54(5), 2677-2682.

Colbeck, S. C. 1986. Classification of seasonal snow cover crystals. Water Resour. Res., 22 (9), 59S-70S.

Colbeck, S. C. 1988. On the micrometeorology of surface hoar growth on snow in mountainous area. Boundary-Layer Meteorol., $44(1-2), 1-12$.

Colbeck, S.C. 1990. Correspondence. Vapor-pressure dependence on temperature in models of snow metamorphism. F. Glaciol., 36(124), 351-353.

Colbeck, S. C. 1993. The vapor diffusion coefficient for snow. Water Resour. Res., 29(1), 109-115.

Colbeck, S.C. and 7 others. 1990. The international classification for seasonal snow on the ground. Wallingford, Oxfordshire, International Association of Scientific Hydrology. International Commission on Snow and Ice.

De Quervain, M. R. 1958. On metamorphism and hardening of snow under constant pressure and temperature gradient. International Association of Scientific Hydrology Publication 46 (General Assembly of Toronto 1957 - Snoze and $I(c), 225-239$.

De Quervain, M. R. 1973. Snow structure, heat, and mass flux through snow. International Association of Hydrological Sciences Publication 107 (Symposium at Banff 1972 - The Role of Snow and Ice in Hydrology), Vol. 1, 203226.

Dullien, F. A. L. and P. N. Mehta. 1972. Particle size and pore (void) size distribution determination by photomicrographic methods. Powder Technol., 5, 179-193.

Friedman, G. M. and J. E. Sanders. 1983. Principles of sedimentology. New York, etc., John Wiley and Sons.

Friedman, I., C. Benson and J. Gleason. 1991. Isotopic changes during snow metamorphism. In Taylor, H. P., Jr, J. R. O'Neill and I. R. Kaplan, eds. Stable isotope geochemistry: a tribute to Samuel Epstein. Washington, DC, Geochemical Society, 211-221. (Special Publication 3.)
Fukue, M. 1977. Mechanical performance of snow under loading. (Ph.D. thesis, Tokai University.)

Granberg, H. B. 1985. Distribution of grain sizes and internal surface area and their role in snow chemistry in a sub-Arctic snow cover. Ann. Glaciol., 7, $149-152$.

Gubler, H. 1985. Model for dry snow metamorphism by interparticle vapor flux. J. Geophys. Res., 90(D5), 8081-8092.

Johnson, J. B., M. Sturm, D. K. Perovich and C. S. Benson. 1987. Field observations of thermal convection in a sub-Arctic snow cover. International Association of Hydrological Sciences Publication 162 (Symposium at Davos 1986 - Avalanche Formation, Movement and Effects), 105-116.

Keeler, C. M. 1969. The growth of bonds and the increase of mechanical strength in a dry seasonal snow-pack. F. Glaciol., 8 (54), 441-450.

Knight, C. A. and A. L. DeVries. 1985. Growth forms of large frost crystals in the Antarctic. 7. Glaciol., 31 (108), 127-135.

Koch, J. P. and A. Wegener. 1930. Wissenschaftliche Ergebnisse der dänischen Expedition nach Dronning Louises-Land und quer über das Inlandeis von Nordgrönland 1912-13. Medd. Gronl., 75.

Kojima, K. 1959. [The influence of temperature gradient upon the grain texture, settling rate and brittleness of snow.] Low Temp. Sci., Ser. A 18 29-45. [In Japanese with English summary.]

Kry, P. R. 1975. Quantitative stereological analysis of grain bonds in snow. f. Glaciol., $14(72), 467-477$.

Lang, R. L., B. R. Leo and R. L. Brown. 1985. Observations on the growth process and strength characteristics of surface hoar. Proceedings, International Snow Science Workshop, 24-27 October 1984, Aspen, CO. Aspen, CO, ISSW Workshop Committee, 188-195.

Ludwick, J. C. and P. L. Henderson. 1968. Particle shape and inference of size from sieving. Sedimentology, 11, 197-235.

Marbouty, D. 1980. An experimental study of temperature-gradient metamorphism. F. Glaciol., 26 (94), 303-312.

National Research Council of Canada. 1954. The international classification for snow. Ottawa, Ont., National Research Council of Canada. Associate Committee on Soil and Snow Mechanics. (ACSSM Technical Memorandum 31 .

Nyberg, A. 1938. Temperature measurements in an air layer close to a snow surface, Geogr. Ann., 20 (3-4), 234-275.

Paulcke, W. 1934. Ice formation. I. Snow and its metamorphosis. Z Gletscherkd., 21, 259-282.

Royse, C.F. 1970. An introduction to sediment analysis: class notes. Tempe, AZ, Arizona State University.

Seligman, G. 1936. Snow structure and skifields. London, Macmillan.

Sturm, M. 1989. The role of thermal convection in heat and mass transport in the subarctic snow cover. (Ph.D. thesis, University of Alaska, Fairbanks.)

Sturm, M. 1991. The role of thermal convection in heat and mass transport in the subarctic snow cover. CRREL Rep. 91-19.

Sturm, M. and J.B. Johnson. 1991. Natural convection in the subarctic snow cover. 7. Geophys. Res., 96 (B7), 11,657-11,671.

Sturm, M. and J. B. Johnson. 1992. Thermal conductivity measurements of depth hoar. F. Geophys. Res., 97 (B2), $2129-2139$.

Sturm, M., J. Holmgren and G. E. Liston. 1995. Seasonal snow cover classification scheme for local to global applications. J. Climate, 8(5), Part 2, 1261-1283.

Trabant, D. C. 1970. Diagenesis of the seasonal snow cover of interior Alaska. (M.Sc. thesis, University of Alaska, Fairbanks.)

Trabant, D. and C. S. Benson. 1972. Field experiments on the development of depth hoar. Geol. Soc. Am. Mem. 135, 309-322.

Yosida, Z. 1955. Physical studies on deposited snow. I. Thermal properties, Contrib. Inst. Low Temp. Sci., Ser. A 7, 19-74.

Young, H. D. 1962. Statistical treatment of experimental data. New York, McGraw-Hill

\section{APPENDIX A}

\section{GALGULATION OF NUMBER OF GRAINS IN A SAMPLE}

If a snow sample is sieved through $L$ sieves, the total mass in the $j$ th sieve, $M_{j}$, is the sum of the masses of individual grains:

$$
M_{j}=\sum_{i=1}^{N_{j}} m_{i}
$$

where $N_{j}$ is the number of grains in the $j$ th sieve, and the 
mass of the $i$ th grain in that sieve is $m_{i}$. If the average mass of a grain in the $j$ th sieve is $\bar{m}_{j}$, then:

$$
N_{j}=\frac{M_{j}}{\bar{m}_{j}} .
$$

Figure 3 establishes a relationship between $\bar{m}_{j}$ and sieve size. Using this relationship, a value of $\bar{m}_{j}$ was determined for each median sieve size used in the study (defined as the average of the size of the sieve through which a grain passes and the size of the sieve on which it came to rest). $M_{j}$ was determined for each sieve by weighing its contents, and $N_{j}$ was calculated from Equation (A2). The total number of grains in a sample $\left(N_{\mathrm{T}}\right.$; plotted in Figure 7$)$ is:

$$
N_{\mathrm{T}}=\sum_{j=1}^{L} N_{j} .
$$

In this study, we chose to calculate $N_{\mathrm{T}}$ for samples of constant mass $(1 \mathrm{~kg})$. The number of grains per unit volume $(N)$ is:

$$
N=N_{\mathrm{T}} \rho
$$

where $\rho$ is the density of the sample.

Uncertainties in values of $N_{\mathrm{T}}$ were large, chiefly because uncertainties in $\bar{m}_{j}$ were large, particularly for larger grains. We estimate that errors were possibly $\pm 50 \%$.

\section{APPENDIX B}

\section{UNGERTAINTY IN LAYER-TO-LAYER FLUX MEASUREMENTS}

The uncertainties in the calculated value of the flux gradient $\left(\partial J_{v} / \partial z\right)$ can be determined by considering the uncertainties $(e)$ in the measured values of $h, \rho_{\mathrm{s}}$ and $\partial \rho_{\mathrm{s}} / \partial t$ :

snow layer thickness $(h): e_{h}= \pm 3 \mathrm{~mm}$

snow layer density $(\rho): e_{\rho_{\mathrm{s}}}= \pm 8 \mathrm{~kg} \mathrm{~m}^{-3}$

compaction rate $(\partial h / \partial t): e_{\partial \mathrm{h}}= \pm 6 \times 10^{-10} \mathrm{~m} \mathrm{~s}^{-1}$

densification rate $\left(\partial \rho_{\mathrm{s}} / \partial t\right): e_{\partial \rho_{\mathrm{s}}}= \pm 1 \times 10^{6} \mathrm{~kg} \mathrm{~m}^{-3} \mathrm{~s}^{-1}$.

This produces an uncertainty in the calculated value of $\partial J / \partial z$ equal to (Young, 1962):

$$
\begin{aligned}
& e_{\text {total }}= \\
& \quad\left[\left(\frac{\partial h / \partial t}{h} e_{\rho}\right)^{2}+\left(\frac{\partial h / \partial t}{h^{2}} \rho_{\mathrm{s}} e_{\rho}\right)^{2}+\left(\frac{\rho_{\mathrm{s}}}{h} e_{\partial h}\right)^{2}+\left(e_{\partial \rho}\right)^{2}\right]^{\frac{1}{2}}
\end{aligned}
$$

where $\left(h(t)\right.$ and $\rho_{\mathrm{s}}(t)$ are from the curves illustrated in Figures 9 and 10. Using reasonable values for $h, \rho_{\mathrm{s}}, \partial h / \partial t$ and $\partial \rho_{\mathrm{s}} / \partial t$ shows that the uncertainty in the flux gradient is more sensitive to errors in thickness than density and that uncertainty is on the order of $25 \times 10^{-7} \mathrm{~kg} \mathrm{~m}^{-2} \mathrm{~s}^{-1} \mathrm{~m}^{-1}$. 